\title{
Estudio comparativo de las diferentes tecnologías de celdas de combustible
}

\author{
J. ALVARADO-FLORES ${ }^{1}$ \\ 'Universidad Michoacana de San Nicolás de Hidalgo. Facultad de Ingeniería Eléctrica. Santiago Tapia 403. Morelia, Michoacán. México
}

\begin{abstract}
Las celdas de combustible generan electricidad y calor durante la reacción electroquímica que ocurre entre el oxígeno e hidrógeno para formar agua. La tecnología de la celda de combustible es un camino prometedor para proporcionar energía en áreas rurales, donde no hay acceso a la red eléctrica pública, o donde hay un costo enorme en el cableado y transferencia de electricidad. Además, las celdas de combustible, pueden emplearse como fuente de energía, para asegurar la energía eléctrica como por ejemplo, en fuentes de potencia ininterrumpida (uninterruptible power supplies, UPS), estaciones de generación de energía y sistemas de distribución. En este artículo, se hace un estudio comparativo sobre diseño básico, principios de funcionamiento, aplicaciones, ventajas y desventajas de las diversas tecnologías disponibles para celdas de combustible. Además, se comparan las características tecno-económicas de los vehículos que funcionan con celdas de combustible a partir de hidrógeno (Fuel Cell Vehicle, FVC) y vehículos con motor de combustión interna (Internal Combustion Engine Vehicle, ICEV). Los resultados indican que los sistemas de celdas de combustibles tienen un diseño simple, confiabilidad alta, funcionamiento silencioso, alta eficiencia y menor impacto ambiental. El objetivo de este artículo, es servir de una conveniente referencia sobre la generación de energía a partir de las celdas de combustible.
\end{abstract}

Palabras clave: celda de combustible, vehículo con celda de combustible (FCV), motor de combustión interna (ICE), tecnología del hidrógeno.

\section{Comparative study of different fuel cell technologies}

Fuel cells generate electricity and heat during electrochemical reaction which happens between the oxygen and hydrogen to form the water. Fuel cell technology is a promising way to provide energy for rural areas where there is no access to the public grid or where there is a huge cost of wiring and transferring electricity. In addition, applications with essential secure electrical energy requirement such as uninterruptible power supplies (UPS), power generation stations and distributed systems can employ fuel cells as their source of energy. The current paper includes a comparative study of basic design, working principle, applications, advantages and disadvantages of various technologies available for fuel cells. In addition, techno-economic features of hydrogen fuel cell vehicles (FCV) and internal combustion engine vehicles (ICEV) are compared. The results indicate that fuel cell systems have simple design, high reliability, noiseless operation, high efficiency and less environmental impact. The aim of this paper is to serve as a convenient reference for fuel cell power generation reviews.

Keywords: Fuel cell, fuel cell vehicle (FCV), internal combustion engine (ICE), hydrogen technology.

\section{INTRODUCCIÓN}

Las celdas de combustible son básicamente sistemas termodinámicos abiertos. Operan en base a reacciones electroquímicas presentes y a los reactivos consumidos de una fuente externa ${ }^{1,2,3,4}$. Son alternativas favorables a los métodos convencionales de generación de energía eléctrica, con aplicación a escala menor. El hidrógeno y los combustibles hidrocarburos, contienen una cantidad importante de energía química en comparación con los convencionales materiales de baterías; por lo tanto, actualmente se han desarrollado para numerosas aplicaciones energéticas.

El hidrógeno y la tecnología de las celdas de combustible, son prometedores sustitutos de los combustibles fósiles para proveer de energía a las zonas rurales donde no hay acceso a la red pública o cuando el costo de cableado es enorme, así como la transferencia de electricidad. Además, las celdas de combustible se pueden emplear como fuente segura de energía eléctrica en sistemas de alimentación ininterrumpida (uninterruptible power supplies, UPS), estaciones de generación de energía y sistemas de distribución. La tabla 1, muestra una comparación general entre los sistemas de celdas de combustible y otros sistemas de generación de energía ${ }^{5,6,7}$.

De acuerdo a la tabla 1 , se puede observar que el rendimiento más alto, se obtiene en los sistemas de celdas de combustible, en comparación con los sistemas convencionales de distribución de energía. Tienen un diseño simple y también funcionamiento confiable. Además, con el uso del hidrogeno como reactivo, estos sistemas resultan amigables con el medio ambiente produciendo energía limpia y de forma silenciosa ${ }^{8,9,10,11,12,13}$. Actualmente, los sistemas de celdas de combustible se utilizan ampliamente en aplicaciones a pequeña y gran escala, por 
TABLA 1. COMPARACIÓN DE LAS CELDAS DE COMBUSTIBLE CON OTROS SISTEMAS DE GENERACIÓN ELÉCTRICA.

\begin{tabular}{|l|c|c|c|c|}
\hline & $\begin{array}{c}\text { Motor alternativo: } \\
\text { diesel }\end{array}$ & $\begin{array}{c}\text { Generador de } \\
\text { turbina }\end{array}$ & Fotovoltaica & $\begin{array}{c}\text { Celda de } \\
\text { combustible }\end{array}$ \\
\hline Rango de capacidad & $500 \mathrm{~kW}-50 \mathrm{MW}$ & $500 \mathrm{~kW}-5 \mathrm{MW}$ & $1 \mathrm{~kW}-1 \mathrm{MW}$ & $10 \mathrm{~kW}-1 \mathrm{~kW}$ \\
\hline Eficiencia & $35 \%$ & $29-42 \%$ & $6-19 \%$ & $25 \%$ \\
\hline Costo de capital $(\$ / \mathrm{kW})$ & $200-350$ & $450-870$ & 6600 & 1000 \\
\hline $\begin{array}{l}\text { Costo de operación } \mathrm{y} \\
\text { mantenimiento }(\$ / \mathrm{kW})\end{array}$ & $0.005-0.015$ & $0.005-0.0065$ & $0.001-0.004$ & $1500-3000$ \\
\hline
\end{tabular}

ejemplo, en los sistemas combinados de potencia y calor (Co-generation Heat Power/Combined Heat and Power, CHP), sistemas móviles de alimentación, computadoras portátiles y equipo de comunicación militar.

A pesar de todas estas ventajas, existen algunas limitaciones en el uso de las celdas de combustible. Por ejemplo, la vida útil de las celdas, se acorta debido al voltaje e impurezas en el flujo de gases utilizados. Otros retos para el desarrollo tecnológico de las celdas de combustible son: optimizar la densidad de potencia por unidad de volumen, accesibilidad y durabilidad de sus componentes. Cabe mencionar que aunque por varios años no se observó un gran avance, es evidente el progreso de estos dispositivos en años recientes.

\section{PRINCIPIO DE OPERACIÓN DE LAS CELDAS DE COMBUSTIBLE}

Las celdas de combustible generan electricidad y calor a través de una reacción electroquímica que en realidad es una reacción de electrólisis invertida. Esto sucede entre el oxígeno e hidrógeno para formar agua. Existe una variedad de diseños disponibles para celdas de combustible, sin embargo, todos ellos operan con los mismos principios básicos. La principal diferencia en el diseño de las celdas, se basa en las características químicas del electrolito utilizado en cada una ${ }^{3}$. La ecuación 1, muestra la reacción electroquímica y la figura 1 representa el principio de funcionamiento de una celda de combustible.

$$
2 \mathrm{H}_{2}(\mathrm{~g})+\mathrm{O}_{2}(\mathrm{~g}) \rightarrow 2 \mathrm{H}_{2} \mathrm{O}+\text { energía }
$$

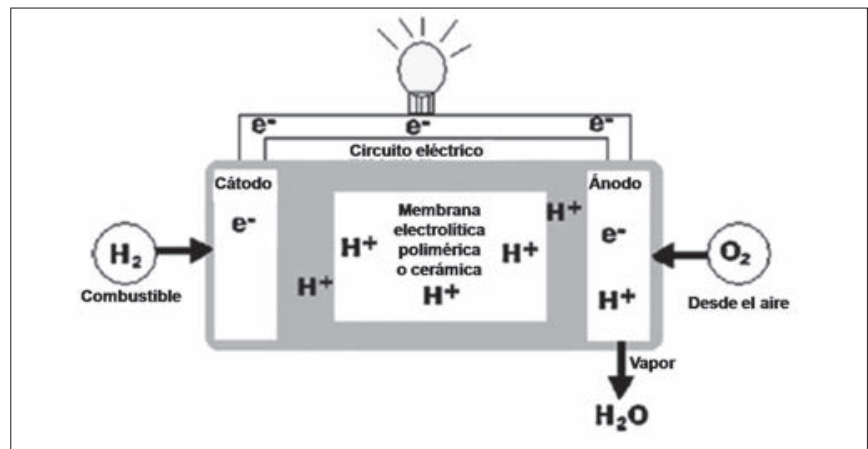

Figura 1. Principio de funcionamiento de una celda de combustible de intercambio protónico.

Una celda de combustible se compone de cuatro partes principales: ánodo, cátodo, electrolito y el circuito externo. En el ánodo, el hidrógeno se oxida, con lo cual resultan protones y electrones, mientras que en el cátodo se reduce el oxígeno a especies óxido, las cuales reaccionan para formar agua. Dependiendo del electrolito, los protones o bien los iones óxido se transportan a través de un conductor iónico aislante, mientras que los electrones viajan a través de un circuito externo para liberar la energía eléctrica ${ }^{4}$. Sin embargo, generalmente las celdas de combustible producen cantidades muy pequeñas de corriente, debido a la reducida área de contacto entre los electrodos, electrolito y gas. Otro problema que se debe considerar es la distancia entre los electrodos. Para mejorar la eficiencia de la celda y maximizar el área de contacto, es necesario una delgada capa electrolítica y electrodos de alta porosidad para la óptima penetración del gas.

La reacción entre el oxígeno e hidrógeno para generar electricidad, es diferente en los distintos tipos de celdas de combustible. En un electrolito ácido, los electrones y protones $\left(\mathrm{H}^{+}\right)$son liberados a partir del gas de hidrógeno hacia el electrodo catódico. Los electrones generados pasan a través de un circuito externo y viajan hacia el cátodo mientras que los protones pasan a través del electrolito. Este intercambio libera energía eléctrica. Simultáneamente, en el lado del cátodo, el agua se forma como resultado de la reacción entre los electrones del electrodo y los protones del electrolito. Las reacciones presentes en el ánodo y cátodo se muestran a continuación:

$$
\begin{aligned}
& \text { Ánodo: } 2 \mathrm{H}_{2} \rightarrow 4 \mathrm{H}^{+}+4 e^{-} \\
& \text {Cátodo }: \mathrm{O}_{2}+4 e^{-}+4 \mathrm{H}^{+} \rightarrow 2 \mathrm{H}_{2} \mathrm{O}
\end{aligned}
$$

\section{TIPOS DE CELDAS DE COMBUSTIBLE}

Las celdas de combustible se pueden clasificar de acuerdo a su temperatura de operación, eficiencia, aplicaciones y costo. En relación al tipo de electrolito utilizado se clasifican en seis grupos principales ${ }^{14}$ :

- Celda de combustible alcalina (Alkaline Fuel Cell, AFC)

- Celda de combustible de ácido fosfórico (Phosphoric Acid Fuel Cell, PAFC)

- Celda de combustible de óxido sólido (Solid Oxide Fuel Cell, SOFC)

- Celda de combustible de carbonatos fundidos (Molten Carbonate Fuel Cell, MCFC)

- Celda de combustible de membrana de intercambio protónico (Proton Exchange Membrane Fuel Cell, PEMFC)

- Celda de combustible de metanol directo (Direct Methanol Fuel Cell, DMFC)

\subsection{Celda de combustible alcalina (Alkaline Fuel Cell, AFC)}

La celda de combustible alcalina ${ }^{15}$, genera energía eléctrica por medio de un electrolito alcalino de hidróxido de potasio $(\mathrm{KOH})$ en solución base agua. La presencia 


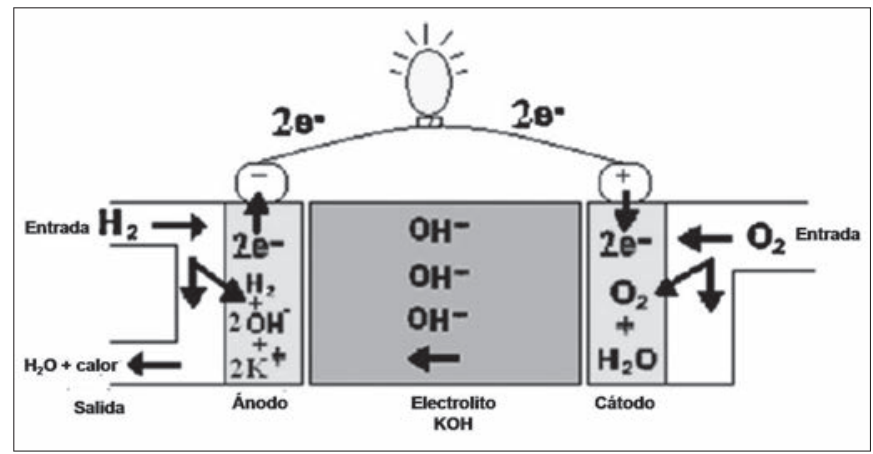

Figura 2. Celda de combustible alcalina (Alkaline Fuel Cell, AFC).

de los iones hidroxilo que viajan a través del electrolito, permite que exista un circuito eléctrico y así la energía eléctrica puede ser extraída. La figura 2, ilustra el mecanismo de operación de una celda de combustible alcalina. En el ánodo, se combinan dos moléculas de hidrógeno gas con cuatro iones hidroxilo con carga negativa, liberándose cuatro moléculas de agua y cuatro electrones. La reacción de oxidación de este proceso, se puede considerar $\operatorname{como}^{16,1}$ :

$$
\text { (oxidación) } 2 \mathrm{H}_{2}+4 \mathrm{OH}^{-} \rightarrow 4 \mathrm{H}_{2} \mathrm{O}+4 e^{-}
$$

Los electrones liberados, reaccionan con el cátodo a través de un circuito externo y reaccionan con el agua para generar iones $\left(\mathrm{OH}^{-}\right)$. En el cátodo, una molécula de oxígeno se combina con dos moléculas de agua y absorben cuatro electrones para formar cuatro iones hidroxilo cargados negativamente. La reacción de reducción que se presenta, es ${ }^{16,17}$ :

$$
\text { (reducción) } \mathrm{O}_{2}+2 \mathrm{H}_{2} \mathrm{O}+4 e^{-} \rightarrow 4 \mathrm{OH}^{-}
$$

Generalmente, la temperatura de funcionamiento de las celdas de combustible alcalinas, se encuentra en el rango de 60 a $90{ }^{\circ} \mathrm{C}$; sin embargo en diseños recientes, estas celdas pueden operar a más bajas temperaturas entre 23 y $70{ }^{\circ} \mathrm{C}$. Estas celdas se consideran de baja temperatura con un costo de catálisis relativamente menor. El catalizador más común utilizado para acelerar las reacciones electroquímicas en el cátodo y ánodo en este tipo de celda de combustible es el níquel. La eficiencia eléctrica de la celda de combustible alcalina, es de aproximadamente $60 \%$ y de más de $80 \%$ de eficiencia con sistema de co-generación de calor y potencia combinados (combined heat and power, $\mathrm{CHP}$ ). En promedio, pueden generar electricidad con una potencia de hasta $20 \mathrm{~kW}^{18,19}$.

La NASA, fue la primera en usar las celdas de combustible alcalinas para abastecer de agua potable y energía eléctrica en las misiones del transbordador espacial. Actualmente, se emplean en submarinos, barcos, montacargas y en aplicaciones de transporte ${ }^{20}$. Debido a su costo, se consideran las más económicas, en relación a que el electrolito que utilizan es hidróxido de potasio $(\mathrm{KOH})$, el cual es un químico estandarizado. Elcatalizador para loselectrodos es deníquel que no es costoso en comparación con otros tipos de catalizadores (metales nobles). Debido a la eliminación de placas bipolares, contienen estructuras simples. Estas, consumen hidrógeno y oxígeno puro para producir agua potable, calor y electricidad. El agua potable producida como sub-producto, es muy útil en naves y transbordadores espaciales. No producen emisión de gases con efecto invernadero y operan con alta eficiencia, aproximadamente $70 \%$. A pesar de todas estas ventajas, las celdas de combustible alcalinas, sufren fácilmente de envenenamiento de dióxido de carbono. La solución alcalina base agua $(\mathrm{KOH})$ utilizada como electrolito, absorbe $\mathrm{CO}_{2}$ en la conversión de $\mathrm{KOH}$ a carbonato de potasio $\left(\mathrm{K}_{2} \mathrm{CO}_{3}\right)$ $\mathrm{y}$, como consecuencia se obtiene el envenenamiento. Por lo tanto, suelen usar aire purificado u oxígeno puro, lo cual aumenta el costo de funcionamiento. Por lo tanto, uno de los retos en estas celdas, es encontrar un sustituto del $\mathrm{KOH}^{6,18}$. Cabe mencionar que actualmente se han realizado diversas investigaciones para integrar las celdas de combustible alcalinas en sistemas de gasificación de carbón con el objetivo de bajar el costo de comercialización, un ejemplo de ello es la unión europea ${ }^{21,22}$. Otro aspecto relevante respecto a estas celdas es su trascendencia internacional, siendo un ejemplo de ello el sistema ubicado en Australia, utilizando la gasificación de carbón ${ }^{23}$. Otra de las innovaciones inteligentes que destaca el uso de estas celdas es la prevención de incendios con el uso $\mathrm{N}_{2}{ }_{2}^{24}$. Recientemente, algunas organizaciones Europeas, han realizado importantes inversiones para el desarrollo de las celdas alcalinas (2.9 millones de Euros), como es el caso de la investigación y desarrollo del proyecto LASER-CELL ${ }^{25}$. Otro proyecto destacable es la construcción de sistemas de celdas de combustible alcalinas, donde se pretende hacer llegar la energía (1MW) suficiente para 500 casas a bajo costo ${ }^{26}$. Para esto es necesario la fabricación en grandes cantidades de las partes constituyentes en la celda, en este ámbito, algunas empresas están desarrollando plantas piloto con la capacidad para producir hasta 20000 electrodos por año ${ }^{27}$. Otro ejemplo de esto, se tiene en el Reino Unido, donde se han invertido 7.5 millones de dólares en el diseño para la celda de combustible alcalina más importante del mundo ${ }^{28}$.

\subsection{Celda de combustible de ácido fosfórico (Phosphoric Acid Fuel Cell, PAFC)}

Las celdas de combustible de ácido fosfórico, considerados como unos de los sistemas más prometedores en la generación de electricidad ${ }^{29}$, utilizan electrodos de papel carbón y un electrolito líquido de ácido fosfórico $\left(\mathrm{H}_{3} \mathrm{PO}_{4}\right)$. La solución de $\mathrm{H}_{3} \mathrm{PO}_{4}(3.09 \%(\mathrm{H}), 31.6 \%(\mathrm{P})$ y $65.3 \%(\mathrm{O}))$ es un líquido transparente e incoloro utilizado en fertilizantes, detergentes, saborizantes para alimentos y productos farmacéuticos. La conductividadiónica delácidofosfórico, es baja en temperaturas reducidas entre 150 y $220^{\circ} \mathrm{C}$. El portador de carga en este tipo de celda de combustible, es el ion hidrógeno ( $\mathrm{H}^{+}$o protón). Pasan del ánodo al cátodo a través del electrolito y los electrones generados, vuelven al cátodo a través del circuito externo y

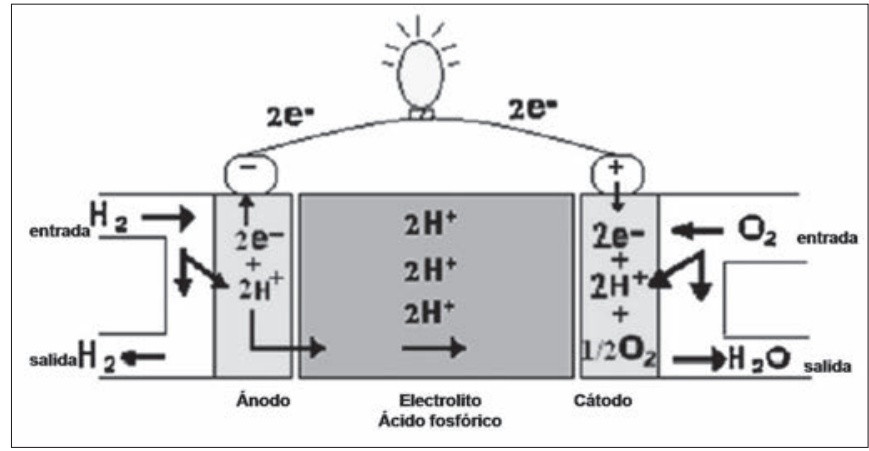

Figura 3. Celda de combustible de ácido fosforico (Phosphoric Acid Fuel Cell, FAFC). 
generan la corriente eléctrica. En el electrodo catódico, el agua se forma como resultado de la reacción entre los electrones, protones y el oxígeno en presencia de un catalizador de platino para acelerar las reacciones. Normalmente, el agua generada, se utiliza en aplicaciones de calentamiento. Cabe resaltar, que la operación continua del sistema a $40{ }^{\circ} \mathrm{C}$ es una preocupación constante, debido a la solidificación del ácido fosfórico a esta temperatura ${ }^{30,31,32,33}$. La figura 3, muestra una celda de combustible de ácido fosfórico.

Como se observa en la figura, el hidrógeno generado en el ánodo, se divide en cuatro protones y cuatro electrones. La reacción redox que tiene lugar en la oxidación del ánodo se muestra en la ecuación 6. Mientras que en el cátodo se tiene la reacción de reducción (Ec.7), donde cuatro protones y cuatro electrones se combinan con el oxígeno para forma agua ${ }^{31,32,33}$.

(oxidación) $2 \mathrm{H}_{2} \rightarrow 4 \mathrm{H}^{+}+4 e^{-}$

(reducción) $\mathrm{O}_{2}+4 \mathrm{H}^{+}+4 e^{-} \rightarrow 2 \mathrm{H}_{2} \mathrm{O}$

Los electrones y protones, pasan a través del circuito externo y electrolito respectivamente. Como resultado se tiene la generación de corriente eléctrica y calor. Normalmente, el calor se utiliza para el calentamiento del agua o generación de vapor a presión atmosférica, sin embargo, las reacciones del reformado de vapor, produce cierta cantidad de monóxido de carbono (CO) alrededor de los electrodos, lo cual puede producir envenenamiento en la celda y afectar severamente su rendimiento. La solución para reducir la absorción de CO, es aumentar el rango de tolerancia del ánodo en relación a su temperatura. En altas temperaturas, el CO se libera en sentido contrario en la reacción de electrocatálisis en el cátodo. Contrariamente, a otros electrolitos ácidos que necesitan agua para efectuar la conductividad, el ácido fosfórico concentrado en la celda, es capaz de operar en temperaturas mayores al punto de ebullición del agua.

Una celda de combustible de ácido fosfórico, no requiere oxígeno puro para su funcionamiento, ya que el $\mathrm{CO}_{2}$ no afecta el electrolito o el rendimiento de la celda. También, se pueden operar fácilmente en combustibles fósiles reformados. Además el ácido $\mathrm{H}_{3} \mathrm{PO}_{4^{\prime}}$ posee baja volatilidad y aceptable estabilidad a largo plazo. El costo inicial de este tipo de celda, es alto, en razón a que utiliza aire con $\sim 21 \%$ de oxígeno en lugar de oxígeno puro, lo cual reduce hasta tres veces, la densidad de corriente. Por lo tanto, las celdas están diseñadas en placas bipolares apiladas para aumentar el área del electrodo, y producir más energía, lo cual implica un alto costo inicial en esta tecnología. Actualmente, los sistemas con celda de combustible de ácido fosfórico, están en la etapa comercial con capacidad de hasta $200 \mathrm{~kW}^{34}$, además existen sistemas ya probados de mayor capacidad de hasta $11 \mathrm{MW}$. Estas celdas, son de fabricación costosa, en relación a la necesidad que tienen de un recubrimiento de platino (catalizador) finamente dispersado en los electrodos. A diferencia de las celdas de combustible alcalina (Alkaline Fuel Cell, AFC), las impurezas del vapor de hidrógeno $\left(\mathrm{CO}_{2}\right)$, no afectan a estas celdas. La eficiencia eléctrica de este tipo de celdas de combustible varía entre 40 y $50 \%$ y se obtiene eficiencia con CHP cerca del $85 \%$. Suelen utilizarse en aplicaciones estacionarias in-situ ${ }^{30,31,32,33}$. Como se puede observar, un aspecto importante en este tipo de celdas es la óptima concentración del electrolito para diferentes temperaturas, así como el rendimiento, eficiencia y sobrepotencial (activación, concentración, óhmico, etc.) ${ }^{35}$.
Recientemente, también se ha propuesto el cambio del electrolito de ácido fosfórico por electrolitos base pasta de fosfosilicatos, resultando una alternativa prometedora en temperaturas intermedias para este tipo de celda ${ }^{36}$.

\subsection{Celda de combustible de óxido sólido (Solid Oxide Fuel Cell, SOFC)}

Las celdas de combustible de óxido sólido, se caracterizan por utilizarse en alta temperatura, conformadas de un electrolito cerámico sólido. En la figura 4, se muestra un ejemplo de esta celda. Generalmente, se utilizan una mezcla de hidrógeno y monóxido de carbono formado internamente por el reformado del hidrocarburo como combustible, además del aire como oxidante ${ }^{4}$. La circonia estabilizada con itria (Yttria Stabilized Zirconia, YSZ) es el electrolito más utilizado para este tipo de celdas, debido a su elevada estabilidad química y térmica, además de su alta conductividad iónica ${ }^{37,38,39}$.

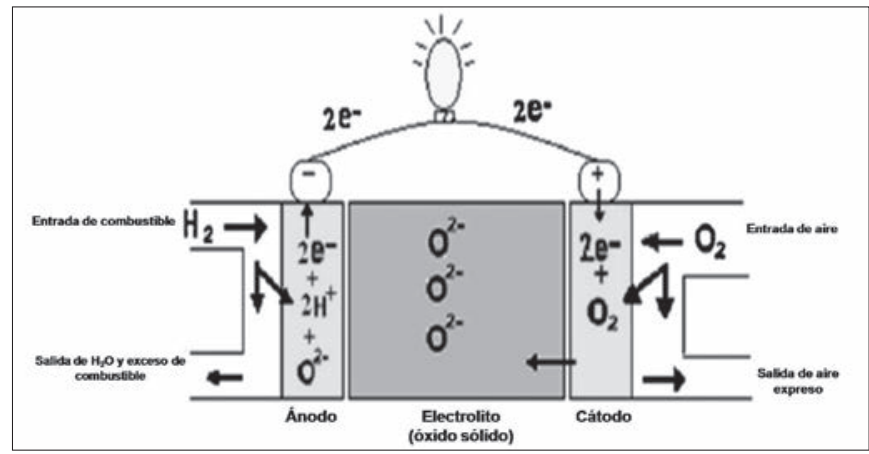

Figura 4. Celda de combustible de óxido sólido (Solid Oxide Fuel Cell, SOFC).

El oxígeno se reduce de acuerdo a la reacción de reducción del cátodo aproximadamente a $1000{ }^{\circ} \mathrm{C}$, para lo cual se requiere que su fabricación/ $\operatorname{síntesis~}^{40}$ y su morfología se la óptima ${ }^{41}$. Mientras que la oxidación del combustible, sucede en el ánodo. El ánodo debe ser poroso para conducir combustible y transportar los productos de la oxidación lejos del electrolito y de la interface electrodo-combustible ${ }^{42,43,44}$. Es importante resaltar el efecto catalítico de algunos elementos como el $\mathrm{Ni}^{45}$ (en combinación con el metano), el cual se ha utilizado ampliamente como parte del ánodo en este tipo e celdas.

$$
\begin{aligned}
& \text { (oxidación) }(1 / 2) \mathrm{O}_{2}(g)+2 e^{-} \rightarrow \mathrm{O}^{2-}(s) \\
& \text { (reducción) } \mathrm{O}^{2-}(s)+\mathrm{H}_{2}(g) \rightarrow \mathrm{H}_{2} \mathrm{O}(\mathrm{g})+2 e^{-}
\end{aligned}
$$

Las celdas de combustible de óxido sólido, son sistemas de generación de potencia de gran escala, con capacidad de cientos de MW. El calor generado como subproducto, generalmente, se utiliza para generar más electricidad, haciendo girar turbinas de gas y por lo tanto, aumenta la eficiencia con sistemas combinados (Combined Heat and Power, CHP) entre 70 y $80 \% 46,47,48$. Este tipo de celdas, son fiables, modulares y adaptables a varios combustibles con bajas emisiones de gases nocivos tales como $\mathrm{NO}_{x}$ y $\mathrm{SO}_{\mathrm{x}}$. Dentro de los combustibles alternativos al hidrógeno, existen otros hidrocarburos tales como metano, propano, butano; así como bioalcoholes dentro de los cuales se encuentran el etanol y metanol; realizando el reformado con vapor de agua o bien mediante oxidación parcial. Ello es posible porque no usan 
catalizadores basados en metales preciosos (platino), debido a sus elevadas temperaturas de operación.

Por otro lado, este tipo de celdas, se pueden considerar como sistemas locales $^{49}$ de generación de energía para zonas rurales que no tienen acceso a las redes públicas. Además, son de funcionamiento silencioso y mantenimiento de bajo costo. Por otro lado, el largo tiempo requerido para iniciar su operación y de enfriamiento, así como diversos problemas de compatibilidad química y mecánica de sus componentes, limita el uso de este tipo de celdas. Varios inv estigadores $^{38,42,43,44,50,51,52}$ han estudiado las posibles soluciones para reducir la temperatura de operación, lo cual pudiera ser la clave para que las celdas de combustible de óxido sólido, sean la nueva generación de dispositivos en la producción de energía eléctrica a gran escala. En este contexto, existen otros materiales alternativos al electrolito YSZ, tales como el GDC (cerio dopado con gadolinio) y el LSGM (galato de lantano dopado con estroncio y magnesio), los cuales se han convertido en los últimos años en serias alternativas, debido a que presentan unas conductividades iónicas similares a la del YSZ a temperaturas más bajas de aproximadamente $200^{\circ} \mathrm{C}$. En concreto, varios estudios han mostrado que el compósito LSGM posee una conductividad electrónica más alta que el $\mathrm{YSZ}^{53,54}$ aunque se ha hecho notar la conductividad iónica equivalente de $\mathrm{YSZ}$ a $1000{ }^{\circ} \mathrm{C}^{55}$. Por otra parte, se menciona que el electrolito LSGM combinado con al ánodo Ni/SDC tiene más probabilidades de éxito a una temperatura entre $700-800{ }^{\circ} \mathrm{C}^{56}$. Con esta combinación también se han encontrado rendimientos comparables a $800{ }^{\circ} \mathrm{C}$ considerando como electrolito al compuesto YSZ, como ánodo al compuesto YSZ/ $\mathrm{Ni}$ y al compuesto LSM/YSZ como cátodo a $1000{ }^{\circ} \mathrm{C}^{57}$. Sin embargo, existen algunos problemas con el electrolito LSGM relacionados con la evaporación del galio a bajas presiones parciales de oxígeno y atmósferas reductoras ${ }^{58}$, dificultades en la producción de películas delgadas ${ }^{59}$, además del costo. Aunque el compósito LSGM ha mostrado mejor rendimiento que el YSZ de igual espesor, muestra dificultades cuando se fabrica con espesores muy pequeños. De acuerdo a algunos investigadores, esto significa que electrolitos de YSZ con un espesor muy pequeño, pueden superar al LSGM en celdas de que operan a temperaturas intermedias con un espesor de $15 \mu \mathrm{m}$. Cabe resaltar que el LSGM también puede formar segundas fases a bajas temperaturas como los compuestos $\mathrm{SrLaGaO}_{7}$ y $\mathrm{La}_{4} \mathrm{Ga}_{2} \mathrm{O}_{9^{\prime}}$ en los límites del electrolito ${ }^{60}$. Es importante resaltar que una alternativa son las celdas micro-tubulares de óxido sólido, las cuales han demostrado interesantes propiedades para aplicarse en sistemas de vehículos futuristas ${ }^{61}$.

Cabe mencionar que, a diferencia de otros tipos de celdas de combustible, las SOFCs presentan dos tipos de configuraciones de apilamiento: planar y tubular. La configuración tubular está compuesta de tubos conectados en serie o en paralelo. Un diseño propuesto por Siemens-Westinghouse el cual proporciona elevada densidad de potencia, ha mejorado en gran medida la conductividad electrónica y se espera utilizar para la producción automática ${ }^{62}$. El diseño planar está compuesto de placas rectangulares o circulares para facilitar el flujo de los reactivos, estos discos combinados en conjunto forman la celda. Los diseños planar y tubular se diferencian por las densidades de potencia que proporcionan ${ }^{63}$. Por ejemplo, las celdas de diseño tubular presentan elevada resistencia eléctrica debido a la distancia que los electrones deben recorrer. Sin embargo, este diseño, proporciona largos periodos de operación (por arriba de 69, 000 horas en un solo tubo). Por otra parte, el diseño planar se considera más efectivo, sin embargo, el modelo planar es costoso comparado con el diseño tubular ${ }^{64}$. El interconector es la parte que se une al cátodo y protege al electrolito de la atmósfera reductora. Los sellos se utilizan en algunos diseños planares y su función es unir los componentes de la celda. El ánodo y el cátodo son porosos y facilitan el transporte de los reactivos y productos a través de los componentes. Cabe mencionar que también son necesarios colectores de corriente, así como hardware diverso para cubrir todos los requerimientos de la celda. Una consideración importante en ambos diseños planar y tubular es reducir la temperatura de operación con el fin de reducir los costos de producción. Específicamente, para los diseños donde su temperatura oscila entre 850 y $1000^{\circ} \mathrm{C}$ (temperatura alta), se puede reducir entre 650 y 750 (temperatura intermedia) o incluso a $500^{\circ} \mathrm{C}$ (temperatura baja). Al reducir la temperatura, se pueden utilizar materiales más económicos por ejemplo los interconectores metálicos. Sin embargo, al reducir la temperatura, se requiere utilizar un electrolito más delgado lo cual requiere de una fabricación especial. Esto puede causar que la densidad de potencia se reduzca limitando el reformado interno de la celda. En la actualidad existen numerosos proyectos en Estados Unidos, Europa y Japón donde se plantea como objetivo una temperatura de trabajo de $400^{\circ} \mathrm{C}$, todo ello a raíz del desarrollo de configuraciones soportadas en metal y la tecnología de capa delgada para la fabricación del electrolito. Sin embargo, algunos autores sugieren que temperaturas menores a $600^{\circ} \mathrm{C}$ no son muy recomendables debido a que se requiere una temperatura mínima de operación cerca a los $1000^{\circ} \mathrm{C}^{65}$. Existen algunas investigaciones destacadas sobre el uso de materiales típicos y configuraciones, así como las ventajas y desventajas de cada diseño, rendimiento, y aplicaciones potenciales ${ }^{66,67,68,69}$. Otras investigaciones están orientadas a las opciones de fabricación de las celdas SOFC realizando un análisis basado en la densidad de los componentes ${ }^{70}$, así como una comparación de los costos en procesos selectos ${ }^{71}$.

\subsection{Celda de combustible de carbonatos fundidos (Molten Carbonate Fuel Cell, MCFC)}

Las celdas de combustible de carbonatos fundidos, son celdas de alta temperatura. Utilizan como electrolito una mezcla de sales de carbonatos fundidos, suspendidos en una matriz cerámica porosa, químicamente inerte y conformada del material beta-alúmina (Beta Alumina Solid Electrolyte, $B A S E)^{72}$. En la figura 5, se ilustra este tipo de celda. La reacción

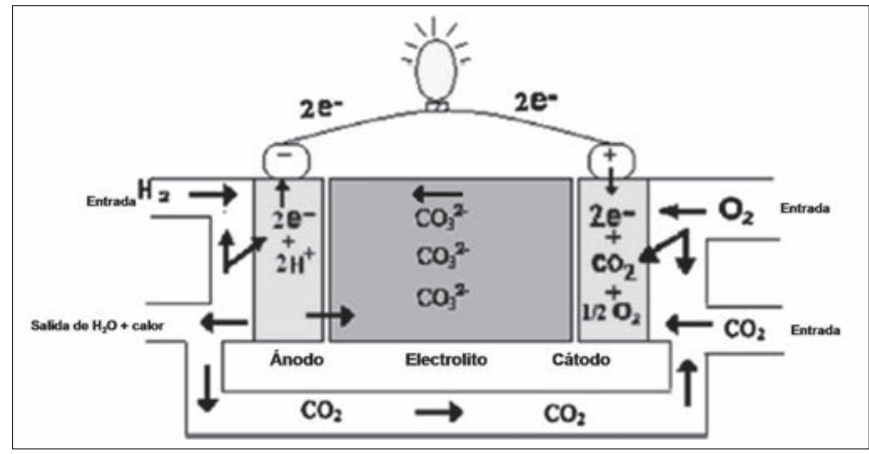

Figura 5. Celda de combustible de carbonatos fundidos (Molten Carbonate Fuel Cell, MCFC). 
en el ánodo, se produce entre el combustible (hidrógeno) y los iones de carbonato, que reaccionan para formar dióxido de carbono, agua y electrones. En el ánodo, el gas de alimentación (generalmente metano $\mathrm{CH}_{4}$ ) y el agua $\mathrm{H}_{2} \mathrm{O}$, se convierten en hidrógeno $\left(\mathrm{H}_{2}\right)$, monóxido de carbono $(\mathrm{CO})$ y dóxido de carbono $\left(\mathrm{CO}_{2}\right)$.

$$
\begin{aligned}
& \text { (Reformado 1) } \mathrm{CH}_{4}+\mathrm{H}_{2} \mathrm{O} \rightarrow \mathrm{CO}+3 \mathrm{H}_{2} \mathrm{O} \\
& \text { (Reformado 2) } \mathrm{CO}+\mathrm{H}_{2} \mathrm{O} \rightarrow \mathrm{CO}_{2}+\mathrm{H}_{2}
\end{aligned}
$$

Simultáneamente, dos reacciones electroquímicas consumen hidrógeno y monóxido de carbono, generando electrones en el ánodo. Ambas reacciones (12) y (13) utilizan los iones carbonatos $\mathrm{CO}_{3}^{2-}$ disponibles en el electrolito:

$$
\begin{aligned}
& \text { (Oxidación 1) } \mathrm{H}_{2}+\mathrm{CO}_{3}^{2-} \rightarrow \mathrm{H}_{2} \mathrm{O}+\mathrm{CO}_{2}+2 e^{-} \\
& \text {(Oxidación 2) } \mathrm{CO}+\mathrm{CO}_{3}^{2-} \rightarrow 2 \mathrm{CO}_{2}+2 e^{-}
\end{aligned}
$$

La reducción ocurre en el cátodo y son expulsados nuevos iones carbonatos a partir del oxígeno $\left(\mathrm{O}_{2}\right)$ y dióxido de carbono $\left(\mathrm{CO}_{2}\right)$. Entonces, los iones carbonatos producidos en el cátodo, se transfieren a través del electrolito hacia el ánodo. La corriente eléctrica y el voltaje de la celda, se transporta a través de los electrones ${ }^{73}$.

$$
\text { (Reducción) }(1 / 2) \mathrm{O}_{2}+\mathrm{CO}_{2}+2 e^{-} \rightarrow \mathrm{CO}_{3}^{2-}
$$

Actualmente, las celdas de combustible de carbonatos fundidos, son empleadas en diversas aplicaciones como centrales eléctricas de servicio público, industria y servicios militares. Hoy en día, se han obtenido buenos resultados en la operación de una celda de combustible de carbonatos fundidos, obteniendo $125 \mathrm{~kW}$ de potencia con el correspondiente balance de energía ${ }^{74}$. Las ventajas y desventajas de este tipo de celdas, están estrechamente relacionadas con su alta temperatura de funcionamiento. Estas celdas, pueden ser alimentadas directamente con hidrógeno, monóxido de carbono, gas natural y propano. No requieren catalizadores de metales nobles para la oxidación y reducción electroquímica. Cabe señalar que si se ha realizado la catálisis por ejemplo del $\mathrm{Ni}-\mathrm{MgO}-\mathrm{Al}_{2} \mathrm{O}_{3}$ para el reformado interno en la celda ${ }^{75}$. Asimismo, no requieren de ningún desarrollo de infraestructura para su instalación, sin embargo, se requiere mucho tiempo para obtener la temperatura de funcionamiento adecuada y generación de energía $a^{73,76,77,78}$. Uno de los aspectos importantes en este tipo de celda de combustible que se debe resaltar, es la dirección del flujo del gas el cual, puede promover la activación del ánodo y el cátodo, e influir en el mejor o menor rendimiento de la celda ${ }^{79}$. En este contexto, también existen diversas investigaciones sobre la posibilidad de utilizar el biogás a partir de residuos, los cuales son tratados en un proceso de digestión anaeróbica, esto también ayudaría en la protección contra el azufre ${ }^{80,81}$. Sin embargo, se debe considerar la reducción en la emisión de $\mathrm{CO}_{2}$, por ejemplo con el uso de ciclos combinados ${ }^{82}$, o aislantes y concentradores adecuados, lo cual también puede funcionar como interesantes sistemas de colectores de carbón en plantas de generación de energía ósil ${ }^{13}$.

\subsection{Celda de combustible de membrana de intercambio protónico (Proton Exchange Membrane Fuel Cell, PEMFC)}

En las celdas de combustible de membrana de intercambio protónico, el hidrógeno es activado por catálisis para formar iónes protonicos y expulsar los electrones del ánodo hacia el cátodo. El protón pasa a través de la membrana mientras que el electrón es forzado a fluir por un circuito externo y por lo tanto generar electricidad. Entoces, el electrón regresa al cátodo, donde interactúa con el oxígeno y el ion protónico para formar agua. Las reacciones químicas que tienen lugar en cada electrodo, se presentan en las ecuaciones (15) y (16). Un ejemplo de este tipo de celda de combustible, se lustra en la figura 6 .

Ánodo: $\mathrm{H}_{2}(\mathrm{~g}) \rightarrow 2 \mathrm{H}^{+}+2 e^{-}$

Cátodo: $(1 / 2) \mathrm{O}_{2}(g)+2 \mathrm{H}^{+}+2 e^{-} \rightarrow \mathrm{H}_{2} \mathrm{O}(\mathrm{l})$

Reacción completa: $\mathrm{H}_{2}(g)+(1 / 2) \mathrm{O}_{2}(g) \rightarrow \mathrm{H}_{2} \mathrm{O}(l)$

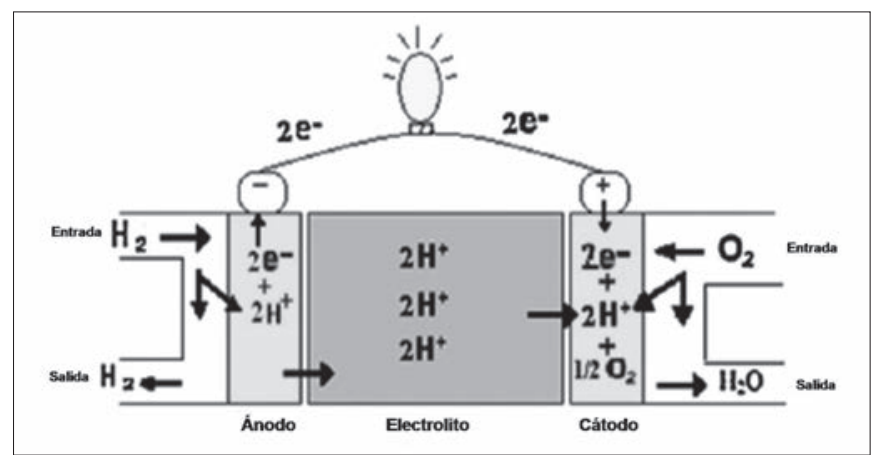

Figura 6. Celda de combustible de membrana de intercambio protónico (Proton Exchange Membrane Fuel Cell, PEMFC).

Básicamente, la celda PEMFC se compone de placas bipolares y ensamblajes electrodos-membrana (electrodemembrana assemblies, MEAs). Este ensamble, se compone de una capa catalizadora dispersa, una capa de carbono o de difusión del gas y la membrana. La membrana sirve para transportar los protones desde el ánodo al cátodo y bloquear el paso de los electrones, así como de los reactivos. De acuerdo a varias investigaciones, la membrana puede ser de Nafion o hidrocarbonada (Hydrocarbon Membrane, HM), utilizando una electrocatálisis semejante. El estudio sugiere la posibilidad de reducir los costos con la membrana HM, sin embargo, el problema de esta membrana es su resistencia eléctrica ${ }^{84}$. El objetivo de la capa de difusión del gas, es que el combustible acceda de manera uniforme a la capa catalítica. Los electrones en el ánodo pasan a través del circuito externo y generan electricidad. Las celdas de combustible de membrana de intercambio protónico, funcionan a baja temperatura entre 60 y $100{ }^{\circ} \mathrm{C}$, sin embargo es importante considerar la acides de las soluciones empleadas (concentración de agua), debido a que se pueden tener problemas de corrosión en las partes metálicas y reducir el tiempo de vida de la celda, por tal motivo, es importante controlar la humedad y temperatura de calentamiento ${ }^{85}$. Las celdas PEMFC, Son sistemas ligeros, compactos y el proceso de inicio de su funcionamiento es rápido. El sellado de los electrodos en estas celdas de combustible, es más fácil que con otros tipos, debido a la solidez del electrolito. Además, tienen un tiempo de vida más largo y su fabricación es más económica ${ }^{86,87,88}$. Una de las aplicaciones más importantes en una PEMFC utilizando hidrógeno de alta pureza, son los equipos portátiles y la industria automotriz, debido a su alta capacidad de almacenamiento, inicio rápido y reacción controlable. Hoy en día, se ha investigado la posibilidad de generar hidrógeno de alta pureza a partir 
de la hidrólisis catalítica de hidruros químicos, por ejemplo utilizando el borohidruro de sodio $\mathrm{NaBH} 4$ y el $\mathrm{Ru}$ como catalizador, obteniendo como resultado un aumento en el rendimiento de la celda de $99.9 \mathrm{~W}$ a $103.45 \mathrm{~W}^{89}$.

Cabe resaltar que, el costo total de un auto con este sistema de celdas, varía de 500-600 dólares por kW, el cual es 10 veces más costoso en comparación con los automóviles que utilizan motor de combustión interna (Internal Combustion Engine, ICE $)^{90}$. El costo total también incluye los costos de montaje, placa bipolar, electrodo de platino, la membrana y elementos periféricos. Desde el punto de vista de eficiencia, a mayor temperatura de operación, la eficiencia aumenta significativamente. Esto se debe a la mayor velocidad de reacción. Sin embargo, con una temperatura de trabajo superior a $100{ }^{\circ} \mathrm{C}$, el agua se puede evaporar y causaría deshidratación a la membrana, la cual permite la reducción en la conductividad protónica. La eficiencia eléctrica de estas celdas de combustible, se encuentra entre 40 y $50 \%$, y la potencia de salida de hasta $250 \mathrm{~kW}$. Los sistemas con celdas de combustible de membrana de intercambio protónico, suelen utilizarse en aplicaciones portátiles y estacionarias. Sin embargo, entre sus aplicaciones, el transporte, parece ser el más apropiado, ya que proporciona un suministro continuo de energía eléctrica con altos niveles de eficiencia y densidad de potencia. Requieren un mínimo de mantenimiento, debido a que no hay partes móviles en el apilamiento de la celda. Los vehículos que funcionan a partir de celdas de combustible (Fuel Cell Vehicle, FCV), son la aplicación más prometedora para utilizar este tipo de celdas. La razón es, la aceptación social en el desarrollo de esta tecnología. Un informe de McNicol y colaboradores $^{91}$, establece que un FCV puede tener un mayor éxito que un vehículo convencional ICE. Sin embargo, el costo inicial de un auto FCV es mucho mayor que un ICE.

Por otro lado, actualmente se han realizado varias modelizaciones con el objetivo de incrementar el intercambio protónico, un ejemplo de ello es la aplicación de un algoritmo de simulación en tiempo real para optimizar los parámetros de diseño y operación de una PEMFC $^{92}$, otros algoritmos se han utilizado en este tipo de celdas, pero considerando diversas temperaturas $\left(150{ }^{\circ} \mathrm{C}, 170{ }^{\circ} \mathrm{C}\right.$ y $\left.190{ }^{\circ} \mathrm{C}\right)$ considerando además modelos en $3 \mathrm{D}^{93}$. En este contexto, también se han realizado estudios sobre modelos de dos dimensiones y aplicando sistemas de ecuaciones por el método de volumen finito para simular la cinética de la electroquímica y la transferencia de masa y calor en la celda, obteniendo interesantes resultados sobre la predicción del comportamiento del hidrógeno y oxígeno, así como la permeabilidad de la celda ${ }^{94}$. También se han realizado modelos en base algoritmos para optimizar la densidad de potencia de la celda a través de curvas de polarización; con lo cual se puede predecir una reducción sustancial en el costo ${ }^{95}$.

\subsection{Celda de combustible de metanol directo (Direct Methanol Fuel Cell, DMFC)}

La celda de combustible de metanol directo, es una celda PEMFC en la que el combustible en lugar de ser $\mathrm{H}_{2}$ es metanol. Cabe resaltar que en esta subclasificación, también se encuentran las celdas de etanol. Son una fuente de energía para fines portátiles, debido a la baja temperatura de operación, larga vida útil y rápido reabastecimiento de combustible. Actualmente, se han realizado investigaciones en este tipo

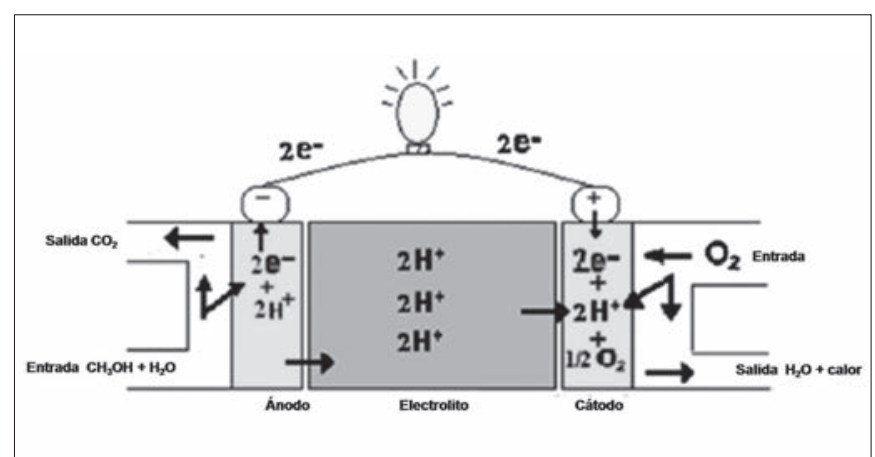

Figura 7. Celda de combustible de metanol directo (Direct Methanol Fuel Cell, DMFC).

de celdas sobre las características de operación considerando temperaturas tan bajas como $-5^{\circ} \mathrm{C}$ a $-10{ }^{\circ} \mathrm{C}$, además del autocalentamiento (generación de calor a partir de la reacción electroquímica correspondiente). Sin embargo, se obtuvo un bajo rendimiento, comparado con el que se obtiene a temperatura ambiente ${ }^{96}$. Cabe resaltar que las celdas DMFC son consideradas como fuentes de energía limpia y renovable. La figura 7, ilustra una celda de este tipo. La fuente de energía de estas celdas es el metanol. En el ánodo, el metanol se transforma a dióxido de carbono $\left(\mathrm{CO}_{2}\right)$ mientras que en el cátodo se forma agua o vapor con el oxígeno disponible en el aire. Las reacciones se muestran en las ecuaciones (18) y (19):

(Ánodo) $\mathrm{CH}_{3} \mathrm{OH}+\mathrm{H}_{2} \mathrm{O} \rightarrow \mathrm{CO}_{2}+6 \mathrm{H}^{+}+6 e^{-}$

(Cátodo) $(3 / 2) \mathrm{O}_{2}+6 e^{-}+6 \mathrm{H}^{+} \rightarrow 3 \mathrm{H}_{2} \mathrm{O}$

Generalmente, las celdas de combustible de metanol directo, se clasifican en sistemas activos y pasivos. Los activos, son sistemas altamente eficientes y confiables. Están constituidos por una bomba para la alimentación del metano, un separador de $\mathrm{CO}_{2}$, el apilado de la celda, un sensor para el metanol, bomba de circulación y controladores de la bomba. El uso de la bomba para la circulación del agua, puede aumentar la eficiencia de cada sistema de forma significativa. Los sistemas activos, normalmente se utilizan en aplicaciones de control, por ejemplo: velocidad de flujo, concentración y temperatura. En los sistemas pasivos, se eliminan los dispositivos de bombeo y de proceso externo para soplar aire en la celda. Por lo tanto, el oxígeno del aire del ambiente se difunde al cátodo. Similarmente, el metanol se difunde en el ánodo a partir de un depósito de alimentación integrado e impulsado por un gradiente de concentración entre el ánodo y el depósito. Los sistemas pasivos son económicos, sencillos y capaces de una reducción sustancial de pérdidas de potencia parásita, así como del volumen del sistema. El metanol se utiliza en las celdas de combustible de metanol directo en forma de vapor o líquido. Es preferible la alimentación por vapor que por líquido, en relación al voltaje y densidad de potencia. Cabe mencionar que, el metanol no realiza de forma adecuada la operación de transferencia de masa y requiere de alta refrigeración localizada en el ánodo. Además, la cantidad de metanol que traspasa del ánodo al cátodo y liberación de gas en la superficie electrocatalizadora, conduce a un menor rendimiento del líquido en la celd $\mathrm{a}^{97}$. Recientemente, varios investigadores han puesto gran atención en la formación de nuevos electrocatalizadores con una elevada actividad en la reacción de reducción de oxígeno, así como alta tolerancia 
al metanol, un ejemplo de esto es el compuesto $\operatorname{Ir}_{x} \mathrm{~S}_{1-\mathrm{x}} / \mathrm{C}$ con $\mathrm{x}=0.7^{98}$. Investigaciones recientes, han mostrado el uso del ionómero (Fumion SO-340 y SO-360) en la catálisis del ánodo en una celda DMFC, observándose tortuosidad dos veces mayor al Nafion, lo cual puede ser producto de la formación de películas de ionómero ${ }^{99}$.

Por otro lado, las celdas alimentadas con vapor, presentan algunos inconvenientes como deshidratación de la membrana, tiempo de vida corto, así como alta temperatura para la vaporización del combustible. Por consiguiente, se requiere de un reformador más complejo y por lo tanto, costoso. Además, no son adecuadas para aplicaciones portátiles (celdas alimentadas con vapor). En las celdas de combustible de metanol directo, se considera a la membrana de intercambio protónico (Proton Exchange Membrane, PEM), como la parte principal, la cual proporciona baja penetrabilidad y alta conductividad protónica. Además, permite alta estabilidad térmica y química para el reformado de la celda. Los polímeros más utilizados para el intercambio perfluorado iónico son el Flemion de Chemical Asahi y el Nafion de Dupont. Estos polímeros, tienen tanto resistencia mecánica como alta hidrofobicidad al ácido sulfúrico, que es más predominante, debido a la presencia de agua. Como consecuencia de ello, la transferencia de agua y metanol a través de la membrana ácida perfluorosulfónica que es un medio de cruce del metanol, tiene un impacto negativo en su rendimiento ${ }^{100,101}$. La membrana de intercambio protónico, se puede modificar para superar este problema de 2 formas: sulfonación y preparación de una membrana compuesta mediante la incorporación de materiales cerámicos inorgánicos ${ }^{102,103}$.

Un aspecto importante que se debe resaltar en las celdas de combustible de metanol directo, son los colectores de corriente para las fuentes de energía, por ejemplo en la portátil, debido a que determinan en gran medida el costo de la celda y la densidad energética. La concentración del metanol y la temperatura de operación pueden afectar el rendimiento de la celda. Actualmente, se han desarrollado colectores de corriente en base oro $(\mathrm{Au})$ cubierto de aluminio $(\mathrm{Al})^{104}$. En comparación con el grafito y el acero inoxidable, se obtuvo un material de características eléctricas superiores, además de un mayor rendimiento obteniendo un valor en la densidad de potencia de $19.8 \mathrm{~mW} \mathrm{~cm}^{-2}$, el cual es mayor al comparar con el grafito $16.34 \mathrm{~mW} \mathrm{~cm}^{-2}$.

\section{COMPARACIÓN DE LAS DIFERENTES TECNOLOGÍAS DE LAS CELDAS DE COMBUSTIBLE}

Las aplicaciones de las celdas de combustible, dependen del tipo de celda a utilizar. Considerando los diferentes tipos de celdas, es necesario aclarar qué tipo de tecnología es la más adecuada, para una aplicación determinada. Las celdas de combustible generan energía eléctrica en un amplio rango de potencias desde el intervalo de los watios, así como de 1 a 10 MW, en casi cualquier aplicación donde se necesite energía. Se pueden emplear en una gama de pequeños dispositivos, por ejemplo en equipos electrónicos personales tales como: teléfonos móviles y computadoras personales (PC). Las aplicaciones a media escala incluyen los vehículos de celda de combustible, aparatos domésticos, aplicaciones militares y transporte público. Finalmente, se pueden utilizar en infinidad de aplicaciones utilizando sistemas de distribución de energía eléctrica de óptima calidad en comunidades de difícil acceso a donde sea muy costosa la implementación del equipo para la generación de electricidad. La tabla 2, es un resumen de

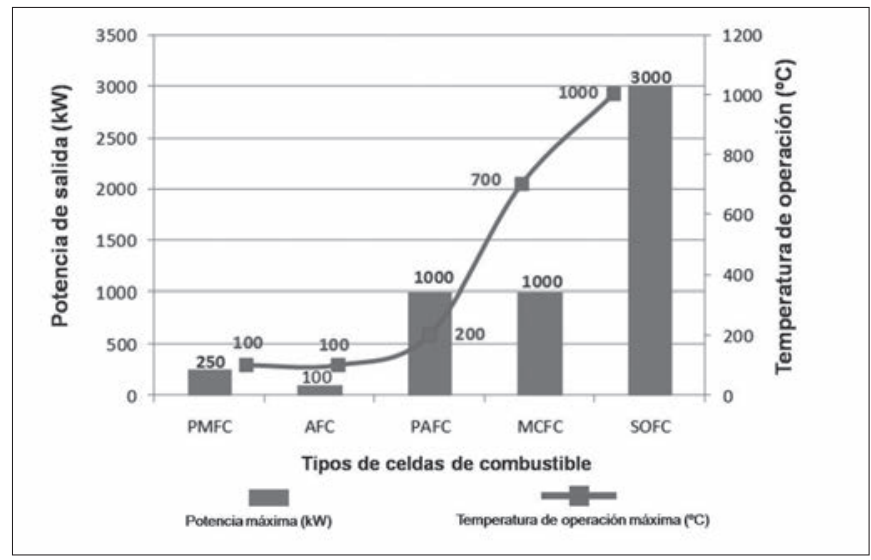

Figura 8. Comparación de la temperatura máxima de operación vs potencia de salida de los diferentes tipos celdas de de combustible.

TABLA 2. RESUMEN DE ESPECIFICACIONES DE FUNCIONAMIENTO EN LA TECNOLOGÍA DE CELDAS DE COMBUSTIBLE.

\begin{tabular}{|c|c|c|c|c|c|c|}
\hline $\begin{array}{l}\text { Tipo de celda de } \\
\text { combustible }\end{array}$ & $\begin{array}{c}\text { AFC } \\
\text { (Alkaline Fuel Cell) }\end{array}$ & $\begin{array}{c}\text { PAFC } \\
\text { (Phosphoric Acid } \\
\text { Fuel Cell) }\end{array}$ & $\begin{array}{c}\text { SOFC } \\
\text { (Solid Oxide Fuel } \\
\text { Cell) }\end{array}$ & $\begin{array}{c}\text { MCFC } \\
\text { (Molten Carbonate } \\
\text { Fuel Cell) }\end{array}$ & $\begin{array}{c}\text { PEMFC } \\
\text { (Proton Exchange } \\
\text { Membrane Fuel } \\
\text { Cell) }\end{array}$ & $\begin{array}{c}\text { DMFC } \\
\text { (Direct Methanol } \\
\text { Fuel Cell) }\end{array}$ \\
\hline $\begin{array}{l}\text { Electrolitos más } \\
\text { comúnmente } \\
\text { utilizados }\end{array}$ & $\begin{array}{c}\text { Solución acuosa } \\
\text { de hidróxido de } \\
\text { potasio sobre una } \\
\text { matriz }\end{array}$ & $\begin{array}{c}\text { Ácido fosfórico } \\
\text { líquido sobre una } \\
\text { matriz }\end{array}$ & $\begin{array}{c}\text { Circonia } \\
\text { estabilizada con } \\
\text { Itria (YSZ) }\end{array}$ & $\begin{array}{c}\text { Carbonatos } \\
\text { fundidos de litio, } \\
\text { sodio y/o potasio }\end{array}$ & $\begin{array}{c}\text { Polímero orgánico } \\
\text { sólido-acido } \\
\text { perfluorosulfónico } \\
\text { (Nafion) }\end{array}$ & Nafion \\
\hline Reacción anódica & $2 \mathrm{H}_{2}+4 \mathrm{OH}^{-} \rightarrow 4 \mathrm{H}_{2} \mathrm{O}+4 \mathrm{e}^{-}$ & $2 \mathrm{H}_{2} \rightarrow 4 \mathrm{H}^{+}+4 \mathrm{e}^{-}$ & $\mathrm{O}^{2-}(\mathrm{g})+\mathrm{H}_{2}(\mathrm{~g}) \rightarrow \mathrm{H}_{2} \mathrm{O}(\mathrm{g})+2 \mathrm{e}^{-}$ & $\mathrm{H}, \mathrm{O}^{\prime}+\mathrm{CO}_{3}^{2-} \rightarrow \mathrm{H}, \mathrm{O}+\mathrm{CO}_{2}+2 \mathrm{e}^{-}$ & $\mathrm{H},(\mathrm{g}) \rightarrow 2 \mathrm{H}^{+}+2 \mathrm{e}^{-}$ & $\mathrm{CH}_{3} \mathrm{OH}+\mathrm{H}_{2} \mathrm{O} \rightarrow \mathrm{CO}_{2}+6 \mathrm{H}^{+}+6 \mathrm{e}^{-}$ \\
\hline Reacción catódica & $\mathrm{O}_{2}+2 \mathrm{H}_{2} \mathrm{O}+4 \mathrm{e}^{-} \rightarrow 4 \mathrm{OH}^{-}$ & $\mathrm{O}_{2}+4 \mathrm{H}^{+}+4 \mathrm{e}^{-} \rightarrow \mathrm{H}_{2} \mathrm{O}$ & $1 / 2 \mathrm{O}_{2}(\mathrm{~g})+2 \mathrm{e}^{-} \rightarrow \mathrm{O}^{2-}(\mathrm{s})$ & $1 / 2 \mathrm{O}_{2}+\mathrm{CO}_{2}+2 \mathrm{e}^{-} \rightarrow \mathrm{CO}_{3}^{2-}$ & $1 / 2 \mathrm{O}_{2}(\mathrm{~g})+2 \mathrm{H}^{+}+2 \mathrm{e}^{-} \rightarrow \mathrm{H}_{2} \mathrm{O}$ & $3 / 2 \mathrm{O}_{2}+6 \mathrm{e}^{-}+6 \mathrm{H}^{+} \rightarrow 3 \mathrm{H}_{2} \mathrm{O}$ \\
\hline $\begin{array}{l}\text { Portador de } \\
\text { carga }\end{array}$ & $\mathrm{OH}^{-}$ & $\mathrm{H}^{+}$ & $\mathrm{O}^{-}$ & $\mathrm{CO}_{3}^{-}$ & $\mathrm{H}^{+}$ & $\mathrm{H}^{+}$ \\
\hline Combustible & $\mathrm{H}_{2}$ puro & $\mathrm{H}_{2}$ puro & $\begin{array}{l}\mathrm{H}_{2^{\prime}} \mathrm{CO}, \mathrm{CH}_{4^{\prime}} \\
\text { otros }\end{array}$ & $\begin{array}{l}\mathrm{H}_{2^{\prime}} \mathrm{CO}, \mathrm{CH}_{4^{\prime}} \\
\text { otros }\end{array}$ & $\mathrm{H}_{2}$ puro & $\mathrm{CH}_{3} \mathrm{OH}$ \\
\hline Oxidante & $\mathrm{O}_{2}$ (aire) & $\mathrm{O}_{2}$ (aire) & $\mathrm{O}_{2}$ (aire) & $\mathrm{O}_{2}$ (aire) & $\mathrm{O}_{2}$ (aire) & $\mathrm{O}_{2}$ (aire) \\
\hline Cogeneración & Sí & Sí & Sí & Sí & Sí & Sí \\
\hline $\begin{array}{l}\text { Voltaje de la } \\
\text { celda }\end{array}$ & 1.0 & 1.1 & $0.8-1.0$ & $0.7-1.0$ & 1.1 & $0.2-0.4$ \\
\hline
\end{tabular}


TABlA 3. COMPARACIÓN DE LAS CARACTERÍSTICAS TÉCNICAS DE LAS CELDAS DE COMBUSTIBLE.

\begin{tabular}{|c|c|c|c|c|c|c|}
\hline $\begin{array}{l}\text { Tipo de celda de } \\
\text { combustible }\end{array}$ & $\begin{array}{l}\text { Temperatura } \\
\text { de operación } \\
\left({ }^{\circ} \mathrm{C}\right)\end{array}$ & $\begin{array}{l}\text { Potencia de } \\
\text { salida }(\mathbf{k W})\end{array}$ & $\begin{array}{l}\text { Eficiencia } \\
\text { eléctrica }(\%)\end{array}$ & $\begin{array}{l}\text { Eficiencia } \\
\text { con sistema } \\
\text { de potencia } \\
\text { y calor } \\
\text { combinados } \\
\text { (CHP) }\end{array}$ & Aplicaciones & Ventajas \\
\hline $\begin{array}{l}\text { Celda de } \\
\text { Combustible } \\
\text { Alcalina } \\
\text { (Alkaline Fuel } \\
\text { Cell, AFC) }\end{array}$ & $90-100$ & $10-100$ & 60 & $>80$ & $\begin{array}{l}\text {-Militar } \\
\text {-Espacial }\end{array}$ & $\begin{array}{l}\text {-La reacción catódica es } \\
\text { más rápida en electrolitos } \\
\text { alcalinos } \\
\text {-Permite alto rendimiento } \\
\text {-Puede utilizar una variedad } \\
\text { de catálisis (electrodos) }\end{array}$ \\
\hline $\begin{array}{l}\text { Celda de } \\
\text { Combustible de } \\
\text { Ácido fosfórico } \\
\text { (Phosphoric Acid } \\
\text { Fuel Cell, PAFC) }\end{array}$ & $150-200$ & $50-1000$ & $>40$ & $>85$ & $\begin{array}{l}\text {-Distribución de } \\
\text { energía }\end{array}$ & $\begin{array}{l}\text {-Alta eficiencia con CHP } \\
\text {-Aumenta la tolerancia a } \\
\text { impurezas en el hidrógeno }\end{array}$ \\
\hline $\begin{array}{l}\text { Celda de } \\
\text { Combustible de } \\
\text { Oxido Sólido } \\
\text { (Solid Oxide Fuel } \\
\text { Cell, SOFC) }\end{array}$ & $600-1000$ & $>1-3000$ & $35-43$ & $<90$ & $\begin{array}{l}\text {-Potencia auxiliar } \\
\text {-Alta distribución } \\
\text { de energía }\end{array}$ & $\begin{array}{l}\text {-Alta eficiencia } \\
\text {-Flexibilidad del combustible } \\
\text {-Puede utilizar una variedad } \\
\text { de catálisis (electrodos) } \\
\text {-Electrolito más delgado } \\
\text { (reduce la caída óhmica) } \\
\text {-Mantenimiento mínimo } \\
\text {-Capacidad para CHP } \\
\text {-Ciclo híbrido/GT }\end{array}$ \\
\hline $\begin{array}{l}\text { Celda de } \\
\text { Combustible } \\
\text { de Carbonatos } \\
\text { Fundidos } \\
\text { (Molten } \\
\text { Carbonate Fuel } \\
\text { Cell, MCFC) }\end{array}$ & $600-700$ & $<1-1000$ & $45-47$ & $>80$ & $\begin{array}{l}\text {-Alta distribución } \\
\text { de energía }\end{array}$ & $\begin{array}{l}\text {-Alta eficiencia } \\
\text {-Flexibilidad del combustible } \\
\text {-Puede utilizar una variedad } \\
\text { de catálisis (electrodos) } \\
\text {-Capacidad para CHP }\end{array}$ \\
\hline $\begin{array}{l}\text { Celda de } \\
\text { Combustible de } \\
\text { Metanol Directo } \\
\text { (Direct Methanol } \\
\text { Fuel Cell, DMFC) }\end{array}$ & $20-90$ & $0.001-100$ & 40 & 80 & $\begin{array}{l}\text {-Computadoras } \\
\text { y otros servicios } \\
\text { portátiles }\end{array}$ & $\begin{array}{l}\text {-Arranque rápido, reducción } \\
\text { de costos. }\end{array}$ \\
\hline
\end{tabular}

TABLA 4. COSTO COMERCIAL DE CELDAS DE COMBUSTIBLE EN PLANTAS CON SISTEMA COMBINADO DE CALOR Y POTENCIA.

\begin{tabular}{|c|c|c|c|c|}
\hline & $\begin{array}{l}\text { (Proton Exchange } \\
\text { Membrane Fuel Cell, } \\
\text { PEMFC) (BPS) }\end{array}$ & $\begin{array}{l}\text { (Phosphoric Acid Fuel } \\
\text { Cell, PAFC) (ONSI) }\end{array}$ & $\begin{array}{l}\text { (Molten Carbonate Fuel } \\
\text { Cell, MCFC) (MTU) }\end{array}$ & $\begin{array}{l}\text { (Solid Oxide Fuel Cell, } \\
\text { SOFC) (SWPC) }\end{array}$ \\
\hline Potencia eléctrica (kWe) & 250 & 200 & 280 & 100 \\
\hline Eficiencia $(\%)$ & 34 & 38 & 48 & 47 \\
\hline Costo $(€ /$ kWe $)$ & $\sim 10,000$ & $\sim 5000$ & $\sim 8000$ & $\sim 20,000$ \\
\hline
\end{tabular}

aBPS: Sistema de potencia Ballard, por ejemplo BEWAG Berlín 250 kWe PEMFC, gas natural, cogeneración.

'ONSI: PAFC 200 kWe, gas natural, cogeneración.

'MTU: Módulo de alta temperatura, por ejemplo, modelo Stardwerke Bielefeld, RWE, MCFC de 250 kWe, gas natural, cogeneración.

¿SWPC: Corporación Siemens WestingHouse, SOFC de100 kWe, cogeneración.

las especificaciones de funcionamiento de la tecnología de las celdas de combustible, mientras que la tabla 3 , presenta las aplicaciones, ventajas y características principales en las celdas de combustible. La figura 8, compara la temperatura de funcionamiento máxima de las celdas frente a la potencia de salida. En general, se obtiene mayor potencia en la medida en que la temperatura sea mayor. La tabla 3, muestra las eficiencias eléctricas y el rendimiento en la producción en combinación de potencia y calor $(\mathrm{CHP})$, de diferentes celdas de combustible. La eficiencia y costos específicos de plantas convencionales con CHP para diferentes sistemas de celdas de combustible, se tabulan en la tabla 4. Los rangos de capacidad de potencia eléctrica varían entre 100 y 300 $\mathrm{kW}^{15,105,106,107,108 \text {. }}$ 


\section{VEHÍCULO ELÉCTRICO CON CELDA DE COMBUSTIBLE (FUEL CELL ELECTRIC VEHICLE, FCEV)}

Existen numerosas aplicaciones de las celdas de combustible. Cada aplicación exige sus propios requisitos también. La mayoría de las aplicaciones de las celdas de combustible se pueden clasificar como:

- Aplicaciones de alta potencia: telecomunicaciones, instalaciones de alta tecnología y procesamiento de datos.

- Minimización o eliminación de emisiones: áreas urbanas, instalaciones industriales, aeropuertos, coches, autobuses y regiones con estrictos estándares de emisiones.

- Aplicación en zonas con acceso limitado a la red de suministro eléctrico: usos portátiles y áreas remotas.

- Aplicabilidad en el manejo de gases de residuos biológicos: plantas tratadoras de residuos.

De todas las aplicaciones de las celdas de combustible, su uso en un vehículo tipo FCEV, ha atraído la mayor atención en los últimos años. Casi todos los fabricantes de vehículos, actualmente presentan investigación y desarrollo (R\&D) en FCEV. Estos, son un tipo especial de vehículos eléctricos construidos con una estructura diferente al motor de combustión interna. En los vehículos convencionales con combustible a diesel o gasolina, la energía es transmitida a partir del combustible desde el motor a las ruedas por un tren de tracción mecánica; sin embargo, en un FCEV, la potencia del tren se obtiene a partir de la electricidad. Estudios recientes ${ }^{109}$, indican que un automóvil híbrido con celda de combustible (FCEV) en

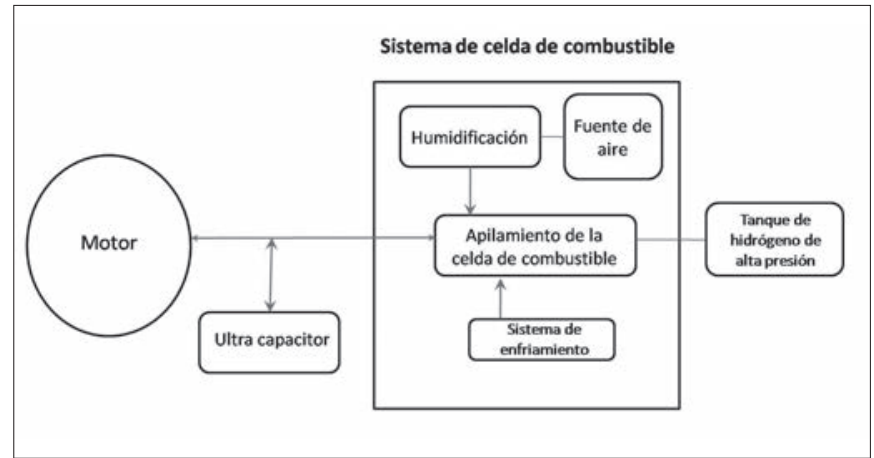

Figura 9. Tren de potencia de un auto hibrido con celda de combustible (Fuel Cell Electric Vehicle, FCEV). combinación con celdas de combustible y un sistema de batería, proporciona en su totalidad mayor eficiencia en comparación cuando solo se utiliza un FCV. Por lo tanto, la preocupación más importante es diseñar y desarrollar dispositivos híbridos tipo FCEVs. Para mejorar la eficiencia de un vehículo mediante el uso de un dispositivo de almacenamiento, se recomienda utilizar una batería o un ultra capacitor "nivelador de carga". Otra sugerencia, es regenerar la potencia de frenado y utilizarla para la aceleración y en pendientes o subidas prolongadas. En la figura 9, se muestra un esquema del tren de potencia para un FCEV híbrido.

Comúnmente, se utiliza un apilamiento de celdas de combustible de membrana de intercambio protónico como fuente de energía para un FCEV, debido a su baja temperatura de operación (cerca de $80^{\circ} \mathrm{C}$ ), densidad de potencia, corriente, tamaño compacto, es ligera, rápida inicialización del sistema y rápido ajuste en la potencia de salida. La tabla 5, muestra los fabricantes de automóviles involucrados en la investigación y desarrollo (R\&D) de los FCEVs. Además, la tabla 5, indica que la mayoría de los fabricantes están utilizando el arreglo de la celda de combustible de membrana de intercambio protónico (Proton Exchange Membrane Fuel Cell, PEMFC), (figura 10).

\section{CELDA DE COMBUSTIBLE DE HIDRÓGENO VS VEHÍCULOS CON MOTOR DE COMBUSTIÓN INTERNA}

Las celdas de combustible generan electricidad como resultado de las reacciones electroquímicas. La principal

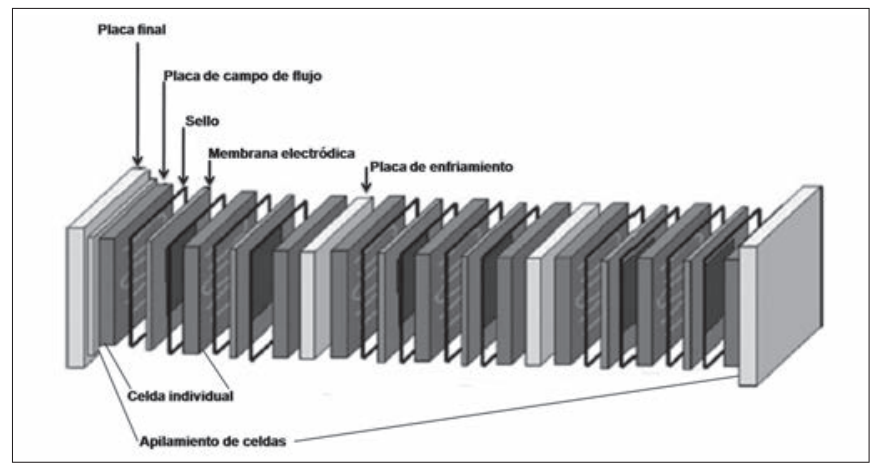

Figura 10. Apilamiento de una celda tipo PEMFC (Proton Exchange Menbrane Fuel Cell).

TABLA 5. FABRICANTES DE AUTOMÓVILES INVOLUCRADOS EN LA INVESTIGACIÓN Y DESARROLLO DE VEHÍ́CULOS ELÉCTRICOS QUE UTILIZAN CELDAS DE COMBUSTIBLE (FUEL CELL ELECTRIC VEHICLE, FCEV).

\begin{tabular}{|l|c|c|c|}
\hline \multicolumn{1}{|c|}{ Compañía } & Tipo de sistema & Celda de combustible & Combustible \\
\hline Daimler-Chrysler & Celda de combustible continua-batería hibrida & Directa-Indirecta & Hidrógeno-Metanol \\
\hline Ford & Celda de combustible continua & Directa/indirecta & Hidrógeno/Metanol \\
\hline General Motors & Celda de combustible-batería híbrida & Directa/indirecta & Hidrógeno/Metanol \\
\hline Honda & Celda de combustible-ultra capacitor híbrido & Directa/indirecta & Hidrógeno/Metanol \\
\hline Mazda & Celda de combustible- batería híbrida & Directa & Hidrógeno \\
\hline Nissan & Celda de combustible- batería híbrida & Indirecta & Metanol \\
\hline Renault & Celda de combustible- batería híbrida & Directa & Hidrógeno \\
\hline Toyota & Celda de combustible- batería híbrida & Directa/indirecta & Metanol \\
\hline Volkswagen & Celda de combustible continua -batería hibrida & Directa/indirecta & Hidrógeno-Metanol \\
\hline ZeTech & Celda de combustible- batería híbrida & Directa & Hidrógeno \\
\hline
\end{tabular}


diferencia en comparación con una batería normal, es que las celdas de combustible son sistemas de generación de energía, mientras que, las baterías son generalmente dispositivos de almacenamiento. En las celdas de combustible, se presenta una reacción entre las moléculas de oxígeno e hidrógeno para formar agua y electricidad, sin embargo, en el proceso de electrólisis, el oxígeno e hidrógeno son expulsados debido al paso de la electricidad a través del agua.

La carga eléctrica externa (motor eléctrico) en un auto, produce un gradiente eléctrico y causa que los electrones fluyan a través de él. Los fabricantes como BMW, General Motors, Nissan, Daimler-Chrysler, Honda, Toyota y Hyundai; han concentrado sus investigaciones en vehículos más eficientes impulsados por hidrógeno. Debido a su eficiencia, los vehículos tipo FCV, son prometedores sustitutos de los autos ICEV, además son más simples, el combustible utilizado es abundante y seguro, sin impactos ambientales (contaminación nula). Cabe mencionar que, con la misma cantidad de combustible, generan mayor potencia de salida en comparación con los motores de combustión interna convencionales (Internal Combustion Engine Vehicle, ICEVs). Las celdas de combustible, tienen una potencia de salida en el rango de 20 y $250 \mathrm{~kW}$, sin embargo, una celda de combustible individual, no puede proporcionar la energía suficiente para poner en movimiento un auto. Por lo tanto se requiere de un "apilamiento de celdas de combustible", es decir, una combinación de varias celdas unidas para generar la suficiente energía y hacer funcionar un automóvil.

La eficiencia de las celdas de combustible es 30 a $90 \%$ mayor que un ICEV que usa gasolina regular. La ventaja más importante y obvia de un vehículo híbrido FCEV de hidrógeno, es que tienen cero emisiones contaminantes. En otras palabras, los vehículos con sistema de energía de celdas de combustible, representan un impacto ambiental bastante reducido, ya que solo producen calor, agua y electricidad. En un auto convencional (ICEV) que utiliza gasolina como combustible, se tienen subproductos como: óxido de azufre $\left(\mathrm{SO}_{2}\right)$, óxido de nitrógeno $\left(\mathrm{NO}_{\chi}\right)$, monóxido de carbono $(\mathrm{CO})$ y dióxido de carbono $\left(\mathrm{CO}_{2}\right)^{6,110,111}$.

Los vehículos híbridos FCEVs (Fuel Cell Electric Vehicle, $F C E V)$ tienen una estructura muy simple en comparación con los autos ICEVs. Son dispositivos que no presentan gran cantidad de partes móviles, y por lo tanto, son silenciosos y de baja vibración. Se elimina la necesidad del aceite de lubricación en los sistemas con celda de combustible (Fuel cell, FC), mediante la reducción de partes mecánicas, por lo que se reducen los gastos de mantenimiento. El tren de potencia del vehículo, esta incrustado en el área de las llantas, de tal manera que el compartimento del motor en el lado frontal del vehículo, también se elimina. Por consiguiente, en los dispositivos FCEV con hidrógeno, son de diseño sencillo, altamente confiables y de funcionamiento silencioso, lo cual permite tener un sistema de larga duración. Sin embargo, al comparar los vehículos tipo FECV y ICEV, se debe tomar en cuenta un análisis económico, así como las diferencias en el costo ${ }^{111,112,113}$. Por ejemplo, se debe considerar la costosa distribución de la infraestructura para automóviles con celda de combustible (FCV). El costo aproximado de un reformador de hidrógeno en una celda es de US \$5000, mientras que el costo de la fabricación de un motor convencional esta alrededor de US $\$ 3000$. El costo de una FC de hidrógeno oscila entre US $\$ 1500$ y US $\$ 3000 / \mathrm{kW}$, mientras que el costo de un
TAbla 6. Costos COMPARATIVOS ENTRE El AUTO CONVENCIONAL DE COMBUSTIÓN INTERNA Y EL VEHÍCULO ELÉCTRICO CON CELDA DE COMBUSTIBLE.

\begin{tabular}{|c|c|c|}
\hline Sistema de propulsión & SI ICE & FC Hibrido \\
\hline Combustible & Gasolina & Hidrógeno \\
\hline Tipo de vehículo & Pasajero & Pasajero \\
\hline Costo inicial & US $\$ 21,717.65$ & US $\$ 21,717.65$ \\
\hline \multicolumn{3}{|l|}{ Motor } \\
\hline $\begin{array}{l}\text { Crédito por Reducción de } \\
\text { dimensión }\end{array}$ & & -US $\$ 6000.00$ \\
\hline \multicolumn{3}{|c|}{ Sistema de celda de combustible } \\
\hline Celda de combustible & & US $\$ 5195.04$ \\
\hline Tanque de combustible & & US $\$ 975.00$ \\
\hline Motor eléctrico & & US \$1558.51 \\
\hline Transmisión de una etapa & & US $\$ 226.50$ \\
\hline Batería & & US \$2597.52 \\
\hline Gases de escape & & -US $\$ 645.00$ \\
\hline \multicolumn{3}{|l|}{ Vehículo } \\
\hline Reducción del peso & & US $\$ 2400.00$ \\
\hline Aerodinámica & & US $\$ 225.00$ \\
\hline $\begin{array}{l}\text { COSTO TOTAL DEL } \\
\text { VEHÍCULO }\end{array}$ & US $\$ 21,717.65$ & US $\$ 28,250.22$ \\
\hline
\end{tabular}

motor de combustión interna (internal combustion engine, ICE) es de US $\$ 50 / \mathrm{kW}$.

Además, las estaciones para el servicio de hidrógeno, requieren de un alto costo de capital para ser construida, aproximadamente US $\$ 470,000$. La modificación de una estación de gas de tamaño promedio costaría alrededor de US $\$ 70,000$. Por lo tanto, el precio de los vehículos FCV con hidrógeno, debe disminuir y además se requieren de otras mejoras económicas para poder efectuar la fase comercial. El primer auto híbrido FECV fue presentado por la empresa Ford. Era bastante caro, sin embargo, la producción en masa ayudó notablemente a reducir los costos ${ }^{6}$.

Investigaciones recientes, mencionan que en Canadá, el costo aproximado de un auto con celda de combustible es de US $\$ 28,300$ comparado con US $\$ 21,700$ de un automóvil con motor de combustión interna ${ }^{112}$. Los resultados muestran hasta un $30 \%$ de diferencia. La tabla 6, compara el precio de los vehículos actuales ICEV con los autos híbridos del futuro de celdas de combustible con hidrógeno FCEV. Se observa que la celda de combustible contribuye en un gasto bastante alto al costo total del sistema. A pesar de que el costo en un auto tipo FCEV es mayor que el ICEV, los costos de funcionamiento y mantenimiento parecen ser convincentes a largo plazo (FCEV).

\section{CONCLUSIÓN}

Se han estudiado los diferentes tipos de celdas de combustible con el objetivo de aclarar la mejor aplicación para cada tipo. Se ha discutido que, aunque todos los tipos de celdas funcionan sobre una base similar; en términos de eficiencia de energía, la alcalina es la más eficiente $(60 \%)$, seguida por la celda de membrana de electrolito polimérico $(58 \%)$ y por último la de carbonatos fundidos 
(47\%). Mientras que las celdas de combustible alcalinas (Alkaline Fuel Cell, $A F C)$, son las más eficientes, la celda de combustible de membrana de intercambio protónico (Proton Exchange Membrane Fuel Cell, PEMFC), es ideal para aplicaciones del transporte tales como automóviles y autobuses. Las celdas de combustible de metanol directo (Direct Methanol Fuel Cell, DMFC) y las celdas de combustible de ácido fosfórico (Phosphoric Acid Fuel Cell, $P A F C)$, son viables económicamente, sin embargo, sufren de baja eficiencia. Las celdas de combustible de óxido sólido (Solid Oxide Fuel Cell, SOFC) y las celdas de combustible de carbonatos fundidos (Molten Carbonate Fuel Cell, MCFC), tienen alto rendimiento y eficiencia en combinación de calor y potencia (Combined Heat and Power, CHP). La comparación de los costos de capital estimado entre un ICEV (Internal Combustion Engine Vehicle) y un FCEV (Fuel Cell Electric Vehicle) muestra que, aunque este último es más caro debido a los costos involucrados con las modificaciones para el sistema de hidrógeno e infraestructura para su distribución, son más convincentes a largo plazo debido al costo operacional y mecánico. Las tecnologías actuales de las celdas de combustible, necesitan ser económicamente más accesibles y superar las ventajas de las tecnologías existentes, para que sean más aceptables y por lo tanto poderse producir en masa. Con el fin de mejorar la viabilidad y aumentar la eficiencia de los autos tipo FCEV, debe realizarse más investigación y desarrollo en institutos de investigación e industrias. Las celdas de combustible ofrecen grandes ventajas importantes sobre el motor de combustión interna (Internal Combustion Engine, ICE) y otros sistemas actuales generadores de energía.

\section{REFERENCIAS}

1. Connihan MA. Dictionary of energy. Routledge and Kegan Paul; 1981

2. Fuel cell, Wikipedia, the free encyclopaedia. Available online at: http:// en.wikipedia.org/wiki/Fuel cell [accessed 08.04.10].

3. Cook B. An introduction to fuel cells and hydrogen technology. Vancouver, Canada: Heliocentris; 2001.

4. Mark Ormerod R. Solid oxide fuel cells, the royal society of chemistry. Chem Soc Rev 2003;32:17-28.

5. Nahar G, Kendall K. Biodiesel formulations as fuel for internally reforming solid oxide fuel cell. Fuel Process Technol 2011;92 (July (7)):1345-1354.

6. Larminie J, Dicks A. Fuel cell system explained. 2nd ed. United Kingdom: John Wiley \& Sons; 2003.

7. Winter M, Brodd RJ. What are batteries, fuel cells, and super capacitors? Chem Rev 2004;104:4245-4269.

8. Zhang X, Shen Z. Carbon fiber paper for fuel cell electrode. Fuel 2002;81 (December (17)):2199-2201.

9. Larrosa-Guerrero A, Scott K, Head IM, Mateo F, Ginesta A, Godinez C. Effect of temperature on the performance of microbial fuel cells. Fuel 2010;89(December (12)):3985-3994

10. Xu H, Kong L, Wen X. Fuel cell power system and high power dc-dc converter. IEEE Trans Power Electron 2004;19:1250-5.

11. http://www.distributed-generation.com/technologies.html.

12. Rayment C, Sherwin S. Introduction to fuel cell technology. Notre Dame, IN, USA: Department of Aerospace and Mechanical Engineering, University of Notre Dame; 2003, May.

13. Grove WR. On voltaic series and the combination of gases by platinum. Philos Mag J Sci 1839;XIV:127-130.

14. Kirubakaran A, Jain S, Nema RK. A review on fuel cell technologies and power electronic interface. Renew Sustain Energy Rev 2009;13:2430-2440.

15. Andújar JM, Segura F. Fuel cells: history and updating. A walk along two centuries. Renew Sustain Energy Rev 2009;13:2309-22.

16. Alhassan M, Garba MU. Design of an alkaline fuel cell. Minna: Federal University of Technology; 2006.

17. Redox reaction, Wikipedia, the free encyclopaedia. Available online at: http:/ / en.wikipedia.org/wiki/Redox reaction [accessed 04.04.10].

18. Crawley G. Fuel cell today. Johnson Matthey Plc. 04241894; 2006, March. Available online at: http:/ / www.fuelcelltoday.com.

19. Comparison of fuel cell technologies. US Department of Energy Hydrogen Program. Available online at: http: / / www.hydrogen.energy.gov [accessed December 2008].
20. Kordesch K. Alkaline fuel cells applications, innovative energy technology. Austria: Institute of High Voltage Engineering, U Graz; 1999.

21. Fuel Cells Bulletin, Volume 2010, Issue 1, January 2010, Pages 5-6.

22. Fuel Cells Bulletin, Volume 2010, Issue 5, May 2010, Page 6.

23. Fuel Cells Bulletin, Volume 2010, Issue 8, August 2010, Pages 5-6.

24. Fuel Cells Bulletin, Volume 2011, Issue 6, June 2011, Page 9.

25. Fuel Cells Bulletin, Volume 2012, Issue 1, January 2012, Page 7.

26. Fuel Cells Bulletin, Volume 2012, Issue 6, June 2012, Page 1.

27. Fuel Cells Bulletin, Volume 2012, Issue 9, September 2012, Page 9

28. Fuel Cells Bulletin, Volume 2012, Issue 12, December 2012, Pages 5-6.

29. Mahendra Pareta, Suman Roy Choudhury, B. Somaiah, J. Rangarajan, N Matre, J. Palande. Methanol reformer integrated phosphoric acid fuel cell (PAFC) based compact plant for field deployment. International journal o f hydrogen energy 36 (2011) $14771-14778$.

30. Remick RJ, Wheeler D, Singh P. MCFC and PAFC R\&D workshop summary report. U.S. Department of Energy; 13 January 2010.

31. Phosphoric acid fuel cell. Irvine: National Fuel Cell Research Centre, University of California; 2009. Available online at: http:/ / www.nfcrc.uci. edu/ EnergyTutorial/pafc.html.

32. Phosphoric acid fuel cell (PAFC). The U.S. Department of Defense (DoD) Fuel Cell Test and Evaluation Centre (FCTec); 2010. Available online at: http:// www.fctec.com/fctec about.asp.

33. Phosphoric acid fuel cell, Wikipedia, the free encyclopaedia. Available online at: http://en.wikipedia.org/wiki/Phosphoric acid fuel cell [accessed 12.01.10].

34. Encyclopedia of Electrochemical Power Sources, 2009, Pages 533-547.

35. Houcheng Zhang, Guoxing Lin, Jincan Chen. Multi-objective optimisation analysis and load matching of a phosphoric acid fuel cell system. International journal of hydrogen energy 37 (2012) 3438-3446.

36. J Fuel Chem Technol, 2012, 40(6), 707-713.

37. Will J, Mitterdorfer A, Kleinlogel C, Perednis D, Gaukler LJ. Fabrication of thin electrolytes for second-generation solid oxide fuel cells. Solid State Ionics 2000;131:79-96.

38. Singhal SC. Advances in solid fuel cell technology. Solid State Ionics 2000;135:305-313.

39. Nicolas Bailly, Samuel Georges, Elisabeth Djurado. Elaboration and electrical characterization of electrosprayed YSZ thin films for intermediate temperature-solid oxide fuel cells (IT-SOFC). Solid State Ionics 222-223 (2012) $1-7$

40. S.R. Gandavarapu et al. / Materials Letters 95 (2013) 131-134.

41. Naveed Akhtar, Stephen P. Decent, Kevin Kendall. A parametric analysis of a micro-tubular, single-chamber solid oxide fuel cell (MT-SC-SOFC). International journal o f hydrogen energy 36 (2011) 765-772.

42. Tanaka K, Wen C, Yamada K. Design and evaluation of combined cycle system with solid oxide fuel cell and gas turbine. Fuel 2000;October (79) (12):1493-507.

43. Sahibzada M, Steele BCH, Barth D, Rudkin RA, Metcalfe IS. Operation of solid oxide fuel cells at reduced temperatures. Fuel 1999;78(May (6)): 639-643.

44. Solid oxide fuel cell, Wikipedia, the free encyclopaedia. Available online at: http:/ / en.wikipedia.org/wiki/Solid oxide fuel cell [accessed 1.04.10].

45. A. Lanzini, P. Leone, C. Guerra, F. Smeacetto, N.P. Brandon, M. Santarelli. Durability of anode supported Solid Oxides Fuel Cells (SOFC) under direct dry-reforming of methane Chemical Engineering Journal 220 (2013) 254-263.

46. V. Liso et al. / Energy 36 (2011) 4216-4226.

47. J. Pirkandi et al. / Journal of Cleaner Production 29-30 (2012) 151-162.

48. S. Wongchanapai, Hiroshi Iwai, Motohiro Saito, Hideo Yoshida. Performance evaluation of a direct-biogas solid oxide fuel cell-micro gas turbine (SOFC-MGT) hybrid combined heat and power (CHP) system. Journal of Power Sources 223 (2013) 9-17.

49. T. Wakui et al. Energy 35 (2010) 740-750.

50. Hibino T, Hashimoto A, Inoue T, Tokuno J, Yoshida S, Sano M. A lowoperating- temperature solid oxide fuel cell in hydrocarbon-air mixtures. Science 2000;16(June):288

51. Shao Z, Sossina M, Halle A. high-performance cathode for the nex generation of solid-oxide fuel cells. Nature 2004;9(September):431.

52. S.M. Majhi, S.K. Behura, S. Bhattacharjee, B.P. Singh, T.K. Chongdar, N.M. Gokhale, L. Besra. Anode supported solid oxide fuel cells (SOFC) by electrophoretic deposition. International journal o f hydrogen energy 36 (2011) 14930-14935.

53. S. Haile, Materials for fuel cells, Mater. Today 6 (2003) 24-29.

54. X. Zhang, S. Ohara, R. Maric, K. Mukai, T. Fukui, H. Yoshida, M. Nishimura, T. Inagaki, K. Miura, NI-SDC cermet anode for medium-temperature solid oxide fuel cell with lanthanum gallate electrode, J. Power Sources 83 (1999) 170-177.

55. J.W. Yan, Z.G. Lu, Y. Jiang, Y.L. Dong, C.Y. Yu, W.Z. Li, Fabrication and testing of a doped lanthanum gallate electrolyte thinfilm solid oxide fuel cell, J. Electrochem. Soc. 149 (9) (2002) A1132-A1135.

56. R. Maric, S. Ohara, T. Fukui, H. Yoshida, M. Nishimura, T. Inagaki, K. Miura, Solid oxide fuel cells with doped lanthanum gallate electrolyte and $\mathrm{LaSrCoO} 3$ cathode and Ni-samaria-doped ceria cermet anode, J. Electrochem. Soc. 146 (1999) 2006-2010. 
57. T. Inagaki, K. Miura, H. Yoshida, R. Maric, S. Ohara, X. Zhang, K. Mukai, T. Fukui, High-performance electrodes for reduced temperature solid oxide fuel cells with doped lanthanum gallate electrolyte. II. $\mathrm{La}(\mathrm{Sr}) \mathrm{CoO} 3$ cathode, J. Power Sources 86 (2000) 347- 351.

58. S.P.S. Badwal, Stability of solid oxide fuel cell components, Solid State Ion. 143 (2001) 39-46.

59. K. Murata, H. Okawa, S. Ohara, T. Fukui, Preparation of $\mathrm{La}(\mathrm{Sr}) \mathrm{Ga}(\mathrm{Mg}) \mathrm{O} 3$ electrolyte film by tape casting method, SOFC VII 368 (2001).

60. B. Steele, A. Heinzel, Materials for fuel-cell technologies, Nature 414 (2001) 345-352.

61. Nigel M. Sammes et al./ The properties and performance of micro-tubular (less than $2.0 \mathrm{~mm}$ O.D.) anode suported solid oxide fuel cell (SOFC). International journal of hydrogen energy 36 (2011) 1882-1889.

62. F. Tietz, Materials selection for solid oxide fuel cells, Mater. Sci. Forum 426-432 (2003) 4465-4470.

63. S.C. Singhal, Solid oxide fuel cells for clean and efficient power generation, Presentation to Boston University, May 30, 2003.

64. S. Adler, Solid oxide fuel cells, Course Notes, Department of Chemical Engineering, University of Washington, 2003.

65. E. Ivers-Tiff'ee, A. Weber, D. Herbstritt, Materials and technologies for SOCF-components, J. Eur. Ceram. Soc. 21 (2001) 1805-1811.

66. J. Larminie, A. Dicks, Fuel Cell Systems Explained, Wiley, 2009.

67. EG\&G Services, Fuel Cell Handbook, 5th ed., 2000. http://www.fuelcells. org/fchandbook.pdf

68. G. Hoogers, Fuel Cell Technology Handbook, CRC Press, New York, 2008.

69. N.Q. Minh, T. Takahashi, Science and Technology of Ceramic Fuel Cells, Elsevier, 1995.

70. J. Will, A. Mitterdorfer, C. Kleinlogel, D. Perednis, L.J. Gauckler, Fabrication of thin electrolytes for second-generation solid oxide fuel cells, Solid State Ion. 131 (2010) 79-96

71. H. Woodward, A performance-based, multi-process cost model for solid oxide fuel cells, Master of Science Thesis, Worcester Polytechnic Institute, 2003

72. Ovshinsky SR, Venkatesan S, Corrigan DA. Molten carbonate fuel cell. United States Patent Application Publication. Pub. No.: US 2006/0204830 A1.

73. Chudej K, Bauer M, Pesch HJ, Schittkowski K. Numerical simulation of a molten carbonate fuel cell by partial differential algebraic equations. Universität Bayreuth; 2008.

74. S. Mekhilef, R. Saidur, A. Safari. The operation results of a $125 \mathrm{~kW}$ molten carbonate fuel cell system. Renewable Energy 42 (2012) 145-151.

75. Hyun-Seog Roh, U.D. Joshi, You-Shick Jung, Yong-Seog Seo, Wang Lai Yoon, Tae-Won Lee. H2 production over co-precipitated $\mathrm{Ni}-\mathrm{MgO}-\mathrm{Al} 2 \mathrm{O} 3$ catalysts for direct internal reforming (DIR) in a molten carbonate fuel cell (MCFC). Journal of Industrial and Engineering Chemistry 18 (2012) 880-881.

76. Chudej K, Bauer M, Pesch HJ, Schittkowski K. Numerical simulation of a molten carbonate fuel cell by partial differential algebraic equations. Universität Bayreuth; 2008

77. Molten Carbonate Fuel Cell, Wikipedia, the free encyclopaedia. Available online at: http://en.wikipedia.org/wiki/Molten carbonate fuel cell [accessed 08.03.10]

78. Gon Lee C, Sam Kang B, Kung Seo H, Chun Lim H. Molten carbonate fuel cell. United States Patent Application Publication. Pub. No.: US 2003/0072989 A1

79. Y.J. Kim, In Gab Chang, Tae Won Lee, Myung Kyoon Chung. Effects of relative gas flow direction in the anode and cathode on the performance characteristics of a Molten Carbonate Fuel Cell Fuel 89 (2010) 1019-1028

80. R. Ciccoli, V. Cigolotti, R. Lo Presti, E. Massi, S.J. McPhail, G. Monteleone, A. Moreno, V. Naticchioni, C. Paoletti, E. Simonetti, F. Zaza. Molten carbonate fuel cells fed with biogas: Combating H2S. Waste Management 30 (2010) 1018-1024

81. Vittorio Verda, Adriano Sciacovelli. Optimal design and operation of a biogas fuelled MCFC (molten carbonate fuel cells) system integrated with an anaerobic digester. Energy 47 (2012) 150-157.

82. Paolo Chiesa, Stefano Campanari, Giampaolo Manzolini. CO2 cryogenic separation from combined cycles integrated with molten carbonate fuel cells. International journal of hydrogen energy 36 (2011) 10355-10365.

83. Gabriele Discepoli, Giovanni Cinti, Umberto Desideri, Daniele Penchini, Stefania Proietti. Carbon capture with molten carbonate fuel cells: Experimental tests and fuel cell performance assessment. International Journal of Greenhouse Gas Control 9 (2012) 372-384.

84. Sunhoe Kim, Inkwon Hong. Membrane performance comparison in a proton exchange membrane fuel cell (PEMFC) stack. Journal of Industrial and Engineering Chemistry 16 (2010) 901-905.

85. Kung-Hsu Hou, Chien-Hung Lin, Ming-Der Ger, Sheau-Wen Shiah, HsiMing Chou. Analysis of the characterization of water produced from proton exchange membrane fuel cell (PEMFC) under different operating thermal conditions. International journal of hydrogen energy 37 (2012) 3890-3896.

86. Sopian K. Challenges and future developments in proton exchange membrane fuel cells. Elsevier Ltd.; 2005.
87. Therdthianwong A, Saenwiset P, Therdthianwong S. Cathode catalyst layer design for proton exchange membrane fuel cells. Fuel, in press, Corrected Proof, Available online 21 July 2011.

88. Comparison of fuel cell technologies. DOE Energy Efficiency and Renewable Energy Information Center; 2008. Available online at: http:/ / www.hydrogen.energy.gov.

89. Huang Z-M, Ay Sua, Ying-Chieh Liu. Hydrogen generator system using $\mathrm{Ru}$ catalyst for PEMFC (proton exchange membrane fuel cell) applications, Energy (2013), http:/ / dx.doi.org/10.1016/j.energy.2013.01.020

90. Tsuchiya H, Kobayashi O. Mass production cost of PEM fuel cell by learning curve. Int J Hydrogen Energy 2004;29(10):985-90.

91. McNicol BD, Rand DAJ, Williams KR. Fuel cells for road transportation purposes-yes or no? J Power Sources 2001;100 (1-2):47-59.

92. Chaohua Dai, Weirong Chen, Zhanli Cheng, Qi Li, Zhiling Jiang, Junbo Jia. Seeker optimization algorithm for global optimization: A case study on optimal modelling of proton exchange membrane fuel cell (PEMFC) Electrical Power and Energy Systems 33 (2011) 369-376.

93. Ai Suzuki, Yuka Oono, Mark C. Williams. Evaluation for sintering of electrocatalysts and its effect on voltage drops in high-temperature proton exchange membrane fuel cells (HT-PEMFC). International Journal of Hydrogen Energy 37 (2012) 18272-18289.

94. Haddad D. Transport phenomena effect on the performance of proton exchange membrane fuel cell (PEMFC). International Journal of Hydrogen Energy 2012), http:/ / dx.doi.org/10.1016/j.ijhydene.2012.11.011.

95. Shan-Jen Cheng, Jr-Ming Miao, Sheng-Ju Wuc. Use of metamodeling optimal approach promotes the performance of proton exchange membrane fuel cell (PEMFC).Applied Energy 105 (2013) 161-169.

96. Young-Chul Park, Dong-Hyun Peck, Sang-Kyung Kim, Seongyop Lim, Doo-Hwan Jung, Dok-Yol Lee. Operation of a direct methanol fuel cell stack by self-heating at low temperatures. International Journal of Hydrogen Energy 36 (2011) 5655-5665.

97. Scott K, Taama WM, Argyropoulos P. Engineering aspects of the direct methanol fuel cell system. J Power Sources 1999;79(1):43-59.

98. Jingyu Ma, Desheng Ai, Xiaofeng Xie, Jianwei Guo. Novel methanoltolerant Ir-S/C chalcogenide electrocatalysts for oxygen reduction in DMFC fuel cell. Particuology 9 (2011) 155-160.

99. K. Wippermann, R. Elze, C. Wannek, H. Echsler, D. Stolten. Influence of the ionomer type in direct methanol fuel cell (DMFC) anode catalyst layers on the properties of primary and secondary poresJournal of Power Sources 228 (2013) 57-67.

100. Hatanaka T, Hasegawa N, Kamiya A, Kawasumi M, Morimoto $\mathrm{Y}$ Kawahara K. Cell performances of direct methanol fuel cells with grafted membranes. Fuel 2002;81(December (17)):2173-2176.

101. Kreuer KA. On the development of proton conducting polymer membranes for hydrogen and methanol fuel cells. J Membr 2001;185(1):29-39.

102. Silva V, Ruffmann B, Silva H, Mendes A, Madeira M, Nunes S. Mass transport of direct methanol fuel cell species in sulfonated poly(ether ether ketone) membranes. J Electrochim 2006;51(May (18)):3699-3706.

103. Silva VS, Weisshaar S, Reissner R, Ruffman B, Vetter S, Mendes A, et al. Performance and efficiency of a DMFC using non-fluorinated composite membranes operating at low/medium temperatures. J Power Sources 2005;145(2):485-494.

104. Zhenyu Yuan, Yufeng Zhang, Jiaxing Leng, Youran Zhao, Xiaowei Liu Performance of air-breathing direct methanol fuel cell with Au-coated aluminum current collectors. International Journal of Hydrogen Energy 37 (2012) 2571-2578

105. Wongyao N, Therdthianwong A, Therdthianwong S. The fading behavior of direct methanol fuel cells under a start-run-stop operation. Fuel 2010;89(May (5)):971-977.

106. Ni H-j, Zhang C-j, Wang X-x, Ma S-y, Liao P. Performance of specialshaped direct methanol fuel cell with sol-gel flux phase. J Fuel Chem Technol 2010;38(October (5)):604-609.

107. Lokurlu A, Grube T, Höhlein B, Stolten D. Fuel cells for mobile and stationary applications-cost analysis for combined heat and power stations on the basis of fuel cells. Int J Hydrogen Energy 2003;28:703-711.

108. Qi A, Peppley B, Karan K. Integrated fuel processors for fuel cell application: a review. Fuel Process Technol 2007;88 (January (1)):3-22

109. Bitsche O, Gutmann G. Systems for hybrid cars. J Power Sources 2004;127 (1-2):8-15.

110. Wang C, Zhou S, Hong X, Qiu T, Wang S. A comprehensive comparison of fuel options for fuel cell vehicles in China. Fuel Process Technol 2005;86(April (7)):831-845.

111. Igot F. Face off: internal combustion engine versus the hydrogen fuel cell. Montgomery College Student J Sci Math 2002;1.

112. Zamel N. Life cycle analysis of vehicles powered by a fuel cell and by internal combustion engine for Canada. J Power Sources 2006;155:297-310.

113. European Commission. Hydrogen energy and fuel cells, a vision of our future; 2003.

Recibido: $27 / 12 / 2012$

Recibida versión corregida: 16/03/2013

Aceptado: 10/05/2013 